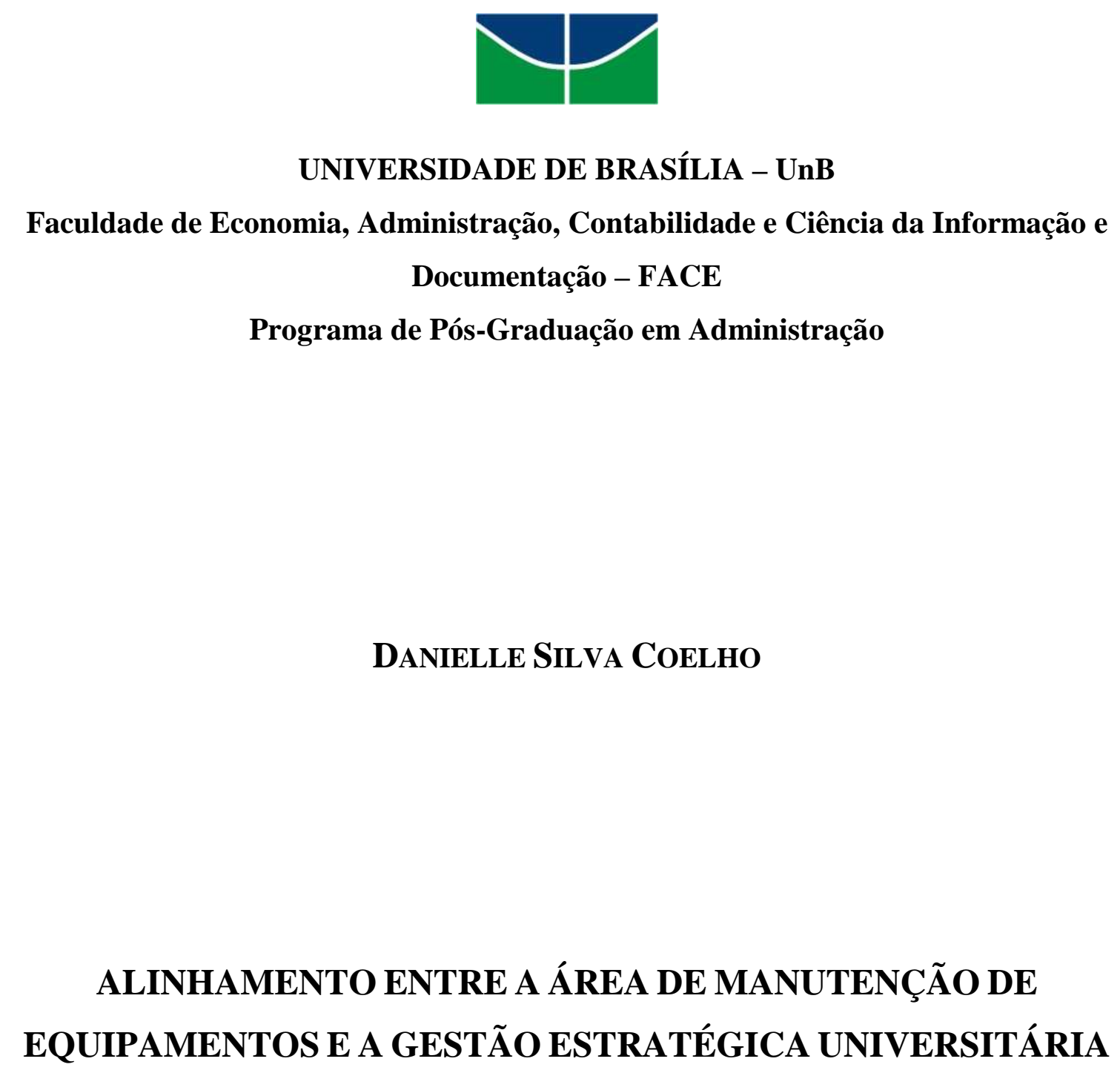

Brasília - DF

2009 
DANIElle Silva CoElHo

\title{
ALINHAMENTO ENTRE A ÁREA DE MANUTENÇÃO DE EQUIPAMENTOS E A GESTÃO ESTRATÉGICA UNIVERSITÁRIA
}

\begin{abstract}
Monografia apresentada ao Programa de PósGraduação em Administração da Faculdade de Economia, Administração, Contabilidade e Ciência da Informação e Documentação (FACE), da Universidade de Brasília, como requisito parcial do grau de Especialista em Gestão Universitária.
\end{abstract}

Orientadora: Prof ${ }^{a}$. MSc. Josivania Silva Farias

\section{Brasília - DF}


Q Dedico este trabatho aos meus fithos, os meus grandes motivadores. 


\section{AGRADEDIMENTOS}

Agradecer é a maior prova de que não estamos sozinhos nesta caminhada.

À Universidade de Brasília

Pela oportunidade de criar e permitir a minha participação nesse curso;

Aos professores do Programa de Pós-Graduação em Administração da FACE

À minha querida e tão competente orientadora Josivania Farias

Pela disponibilidade, puxões de orelha e seriedade na condução da orientação desta monografia;

Aos meus pais Maria do Carmo e Seclyds

Pela compreensão e apoio;

Aos meus pequenos, Laísa e Arthur

Que a cada dia me dão motivação para aprender, ensinar e viver.

Às minhas colegas de sala Rejane, Norma, Lucia Kobayashi, Renata, Sarah, Eliene e, em especial, a minha querida amiga Ilmara bem como todos aqueles que de alguma forma participaram dessa jornada.

Pelas idéias, incentivos e companheirismo Aos meus colegas de trabalho, em especial, Bruna, Mariângela e Reginaldo Lima Pela paciência, compreensão e apoio; Ao meu querido amigo e diretor Francisco Assis Lima Pela compreensão e apoio; 
EPÍGRAFE

Qlma visão sem asão não paśsa de um sonho.

Ascão sem uma visão ésó passatempo.

Q) isão com asãa pode mudar a mundo!

Toel Barker 


\section{RESUMO E PALAVRAS-CHAVE}

Este trabalho tem como objetivo averiguar a influência da área de manutenção de equipamentos no contexto da Gestão Estratégica da Universitária. Como objetivo principal, buscou-se estudar a visão dos servidores/ colaboradores técnico-administrativos da Universidade de Brasília acerca do alinhamento existente entre os serviços de manutenção de equipamentos aplicados à Gestão Estratégica Universitária. Estudo realizado por meio de pesquisa descritiva. A forma de investigar baseia-se em um estudo de caso, onde o universo pesquisado é formado por servidores/ colaboradores técnico-administrativos da Universidade de Brasília. Tem-se como técnica de coleta de dados o questionário estruturado. Os resultados obtidos indicam que existe um alinhamento entre os serviços de manutenção e a Gestão Estratégica da Universidade de Brasília ao mostrar que a área de manutenção um setor de fundamental importância.

Palavras-Chave: Estratégia, Manutenção, Logística, Gestão Estratégica da Manutenção 


\section{LISTA DE TABELAS}

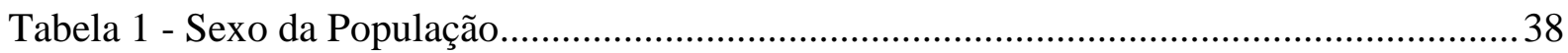

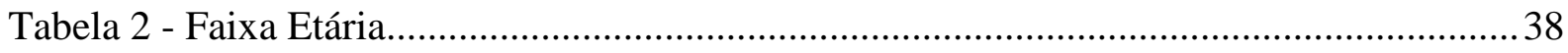

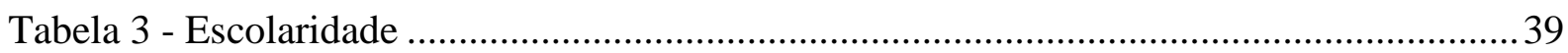

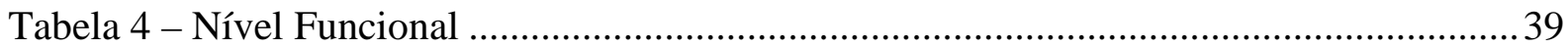

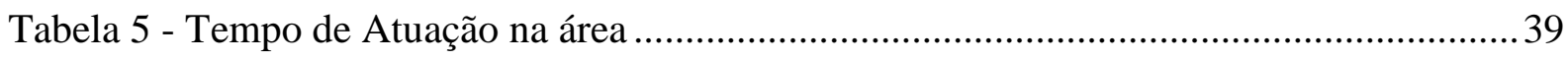

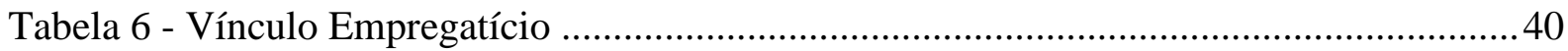

\section{LISTA DE GRÁFICOS}

Quadro 1 - Caracterização da Universidade como uma organização complexa ...................... 16

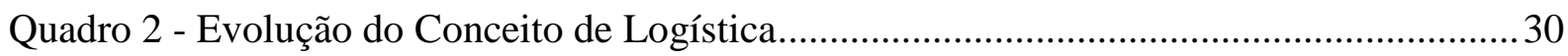




\title{
LISTA DE SIGLAS
}

\author{
ABNT - Associação Brasileira de Normas Técnicas \\ UnB - Universidade de Brasília \\ GEM - Gestão Estratégica da Manutenção
}




\section{SUMÁRIO}

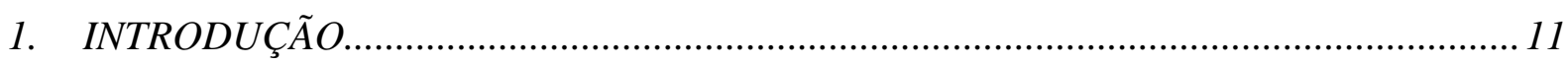

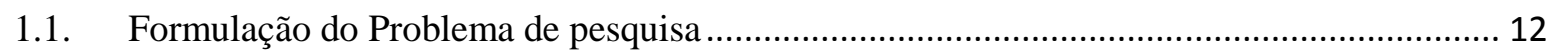

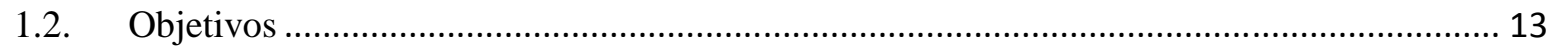

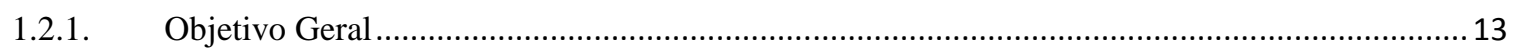

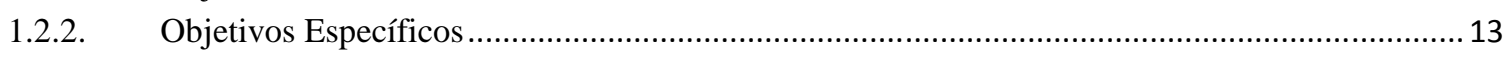

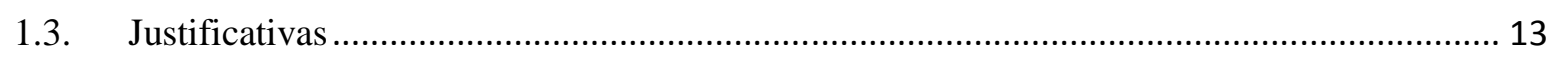

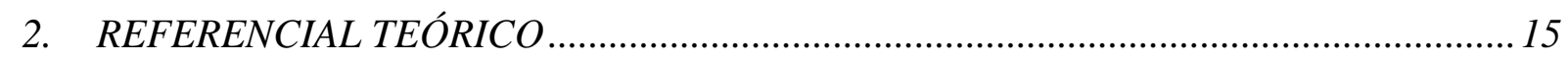

2.1. Aspectos Históricos a respeito da Criação e Evolução das Universidades ............................ 15

2.1.1. A procedência e o desenvolvimento das universidades no mundo............................................... 16

2.1.2. O surgimento, a concepção e a evolução das universidades brasileiras ........................................17

2.2. A Universidade de Brasília - locus do estudo....................................................................... 19

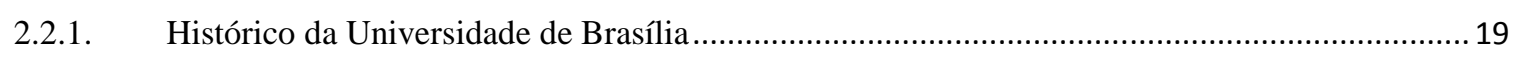

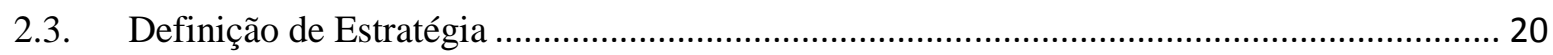

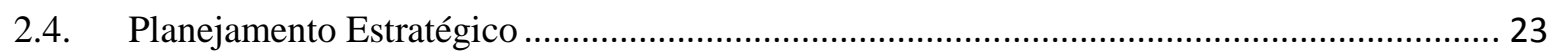

2.5. Conceitos e caracterização dos serviços de manutenção..................................................... 24

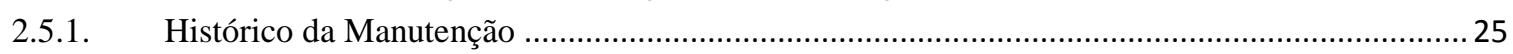

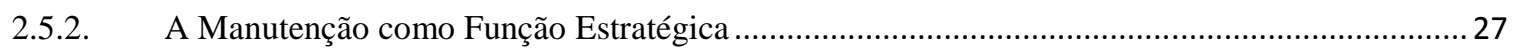

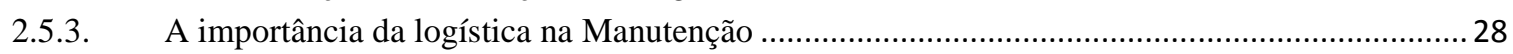

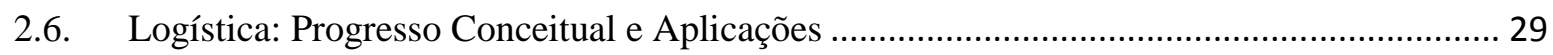

2.7. Gestão Estratégica da Manutenção................................................................................ 32

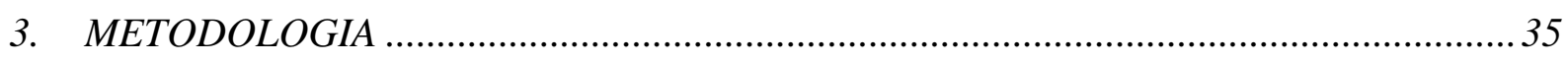

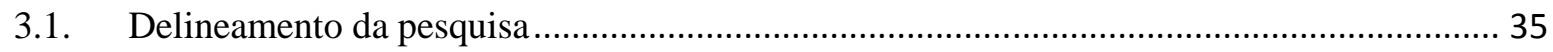

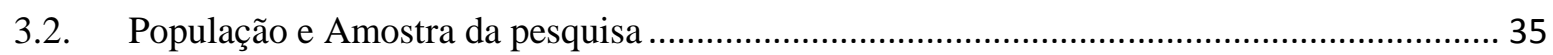

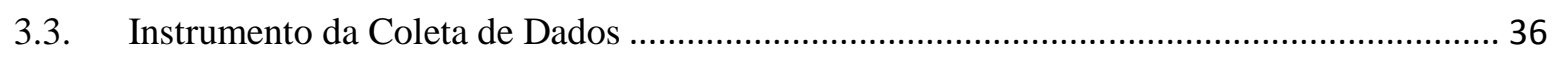

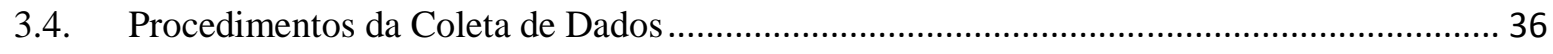

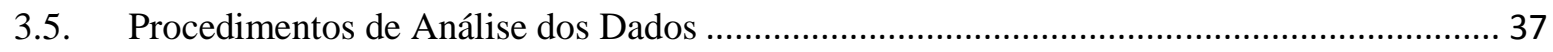

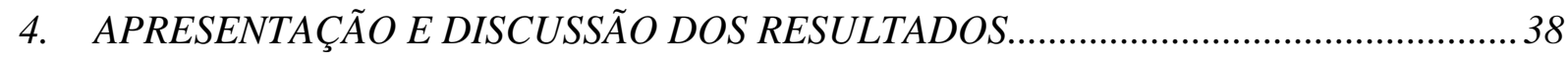

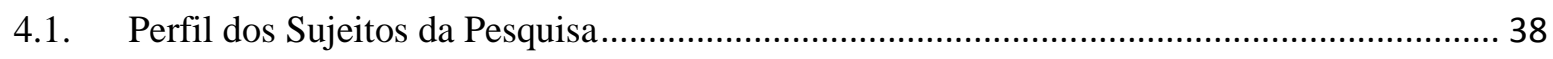

4.2. O papel da função manutenção dentro da Gestão Estratégica Universitária; ......................... 40

4.3. O alinhamento da manutenção com a estratégia da Universidade de Brasília...................... 43

4.4. A eficiência na gestão dos serviços de manutenção como um fator redutor de custos na

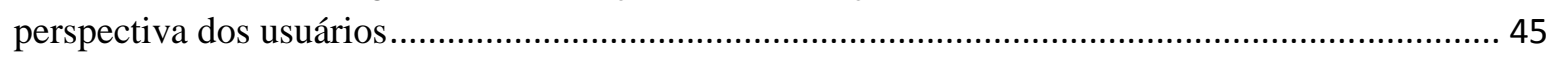

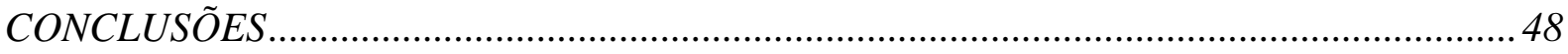


REFERÊNCIAS 


\section{INTRODUÇÃO}

Desde meados do século passado e na atual década a sobrevivência das organizações tem se tornado mais complexa, um mercado em estável processo de mudança preserva somente organizações competentes, lépidas, inovadoras e, sobretudo, vinculadas com esta nova realidade.

Devido a essa referida mudança no ambiente, faz-se necessário que as organizações, de certa forma, reformulem suas ações para que esse alinhamento, perdido com a variação ambiental, seja restabelecido.

Além disso, percebe-se que uma crescente variedade de grupos de interesse, conhecidos como stakeholders, que vem desempenhando grande influência sobre os nortes estratégicos das organizações, conferindo um novo modelo competitivo.

Neste sentido, a necessidade de sobreviver das organizações em meio à globalização tem obrigado às instituições a inovar em métodos de gestão na procura da diminuição de seus custos, visando o avanço da excelência. Do ponto de vista de Meyer Jr (1997 apud ESTRADA, 2000, p. 1), assim como as empresas, "as universidades brasileiras estão necessitando de uma reformulação gerencial de maneira a posicionar-se de forma mais competitiva no ambiente".

As Universidades são o tipo de organização que tem sobrevivido a praticamente todas as mudanças enfrentadas pela sociedade moderna, principalmente pela sua facilidade de se antecipar ou até mesmo de adaptar-se às mudanças, sejam elas econômicas, políticas, tecnológicas como sociais, apresentando um papel especial no desenvolvimento da sociedade.

Dentro desse espírito de mudança, este trabalho volta-se para a Manutenção das Instituições Federais de Ensino Superior, instituições estas, responsáveis pelo desenvolvimento dos profissionais que irão administrar as organizações de todo o tipo e conduzir a sociedade do conhecimento.

Neste crescimento, a Manutenção deixou de ser somente um mal necessário e passou a ser avaliada como um papel fundamental. Quer por meio da ampliação da confiabilidade operacional, quer pela diminuição dos custos inerentes da manutenção, redução de desperdícios, uso coerente dos recursos e tantos outros, a manutenção passou a ser vista como um diferencial em processos e objetivos estratégicos. 
Assim como as Universidades, a manutenção, segundo Moubray (1996 apud SELLITTO, 2005), tem buscado modernos estilos de pensar, técnicos e administrativos, já que as novas reivindicações de mercado tornaram visíveis os obstáculos dos recentes sistemas de gestão onde, uma das mudanças assinaladas pelo autor é a inclusão de subsídios da confiabilidade às estratégias habituais de manutenção deparadas nas instituições.

\subsection{Formulação do Problema de pesquisa}

O setor de serviços representa atualmente um componente mais expressivo do PIB mundial, e conseqüentemente, a gestão de serviços passa a ter amplo valor. Hoje em dia, nos Estados Unidos o quantitativo de trabalhadores neste setor representa mais de $80 \%$, e esta dimensão se reflete em todos os estados globalizados em torno do mundo (BRETHAUER, 2004 apud CARSTENS, 2007).

Justamente por isto, pesquisar estratégias de operações em organizações voltadas para a prestação de serviços é extremamente importante. Os mercados vêm aditando muito valor e importância aos serviços, e um serviço não entregue torna-se perecível, diferente de um produto, pois é inestocável e intangível.

A globalização e a integração econômica entre os países trazem exigências no que diz respeito à necessidade das organizações se reestruturem para alcançar sua própria sobrevivência e desenvolvimento bem como a necessidade de benefícios competitivos tem se refletido no valor de seus produtos devido ao ajuntamento de serviços.

A gestão estratégica, a logística e a manutenção são, conseqüentemente, uma ferramenta muito vantajosa para as organizações da atualidade que almejam ser competitivas no mercado. Reunir gestão estratégica, logística e manutenção, como se observará ao longo deste texto, denota criar mais competências, para racionalizar os custos com a maior produtividade e qualidade possível diante dos novos desafios deste mundo globalizado a que acabamos de nos referir. É oferecer às organizações condições de supervivência perante de tanta competitividade e do aumento de demandas de toda ordem (CUNHA, 2003).

Nesse panorama é importante enfatizar a importância das relações estratégicas devido ao seu papel interdisciplinar. Por outro lado, as universidades passaram a ter uma função ainda mais importante para a sociedade, ao serem inseridas no escopo dos interesses dos mais diversos influenciadores externos, que abrangem desde o governo federal, passando por partidos políticos e o meio empresarial, até sindicatos e representações dos mais variados interesses onde a maneira como as universidades compreendem, estabelecem, disseminam e 
avaliam suas estratégias também se cobre de importância, especialmente em função do aumento da competitividade, com o aparecimento de universidades empresariais competitivas, em um cenário marcado por universidades que estão numa habitual condição de estabilidade.

Neste sentido, e tendo em vista as atuais mudanças de conceito sobre o ambiente universitário, o presente trabalho procura compreender as conseqüências da manutenção na estratégia das Instituições Publica de Ensino Superior, e para isto apresenta-se o problema de pesquisa na forma do seguinte questionamento:

“Há integração estratégica entre as ações da área de manutenção de equipamentos e a formulação e prática de estratégias na Instituição Federal de Ensino Superior estudada?"

\subsection{Objetivos}

\subsubsection{Objetivo Geral}

Averiguar o alinhamento da área de manutenção de equipamentos às ações e ao contexto da Gestão Estratégica da Universitária.

\subsubsection{Objetivos Específicos}

- Traçar o perfil demográfico-funcional dos servidores/ colaboradores da Universidade que atuam na área administrativa que são estão ligados com as ações estratégicas da Universidade bem como com os serviços de manutenção;

- Identificar o papel da manutenção dentro da Gestão Estratégica Universitária;

- Identificar o alinhamento da área de manutenção à estratégia da Universidade de Brasília;

- Verificar se, na perspectiva dos usuários, a eficiência na gestão dos serviços de manutenção de um modo geral pode ser um fator redutor de custos;

\subsection{Justificativas}

A justificativa de se estudar o alinhamento entre a Manutenção e Gestão Estratégica, especificamente de uma Instituição Federal de Ensino Superior, está na 
possibilidade de compreender a gestão da manutenção que caracteriza as organizações desse segmento, e em possibilitar o entendimento da visão empreendedora que se tem em implantar a Gestão Estratégica no setor público.

Pode-se considerar a área de Manutenção de Equipamentos como um tema relevante para estudo devido a sua capacidade de criar um ambiente de melhoria contínua e permitir as organizações elevarem sua atuação a uma classe maior de produtividade (JIPM, 2002 apud MORAES, 2004).

Este ambiente de melhoria junto às organizações e o dinamismo dos investimentos clareiam a necessidade de delinear estratégias de atuação, tendo em vista que os progressos são constantes e acelerados e com heterogeneidade de tecnologias as organizações carecem apresentar muita presteza na sua área operacional a fim de resguardar seus usuários conservando a qualidade dos serviços durante este universo de transformações.

Neste panorama, o desempenho da área de manutenção, torna-se mais importante, e seus impactos na estratégia acendem ainda mais, pois sua disponibilidade compromete inteiramente a qualidade do produto entregue ao usuário, onde o serviço não entregue pode tornar um serviço, um projeto ou até mesmo uma pesquisa totalmente perdida, e que jamais será recuperado. E por estes motivos foi à área escolhida para o estudo de caso deste trabalho.

Há muitos autores que enfatizam a valor do desenvolvimento de estratégias, para assistenciar a concorrência das empresas, todavia a maior parte destes modelos tem como particularidade comum terem sido desenvolvidos para o aproveitamento em indústrias, estando muitas vezes impróprios para emprego nos setores de serviços (SUM; KOW; CHEM, 2004 apud CARSTENS, 2007).

Outro ponto importante que justifica a realização desta pesquisa é a possibilidade de reunir argumentos para melhorar a literatura pertinente, pois ao verificar o alinhamento das ações de manutenção às estratégias da gestão universitária possibilitam verificar se a atuação da área de manutenção da Universidade de Brasília está dentro desse contexto estratégico, contribuindo de forma eficaz para a gestão universitária.

O estudo encontra-se viável devido à fundamentação teórica e programação de tempo hábil para a pesquisa. Do ponto de vista financeiro, a pesquisa não depende de nenhum órgão de fomento à pesquisa. 


\section{REFERENCIAL TEÓRICO}

A procura da compreensão da forma como as organizações funcionam e como são abordadas as questões relacionadas aos seus serviços de manutenção e a interação deste às suas estratégicas, já provocou a prática de alguns estudos na área, estando este tema longe de estar esgotado. Haja vista que a presente pesquisa aborda as relações entre a área de serviços de manutenção e sua vinculação à gestão estratégica no contexto universitário, busca-se apresentar uma abordagem sobre o assunto, partindo para um estudo específico sobre o tema nas Instituições Federais de Ensino Superior.

Primeiramente, busca-se apresentar uma visão ampla sobre a Criação e Evolução das Universidades, seguindo-se uma abordagem sobre a Manutenção, Logística e Gestão Estratégica. Por fim, procura-se abordar a literatura existente com relação à Gestão Estratégica da Manutenção e, mais especificamente, como estas relações interagem no contexto da Gestão Universitária.

\subsection{Aspectos Históricos a respeito da Criação e Evolução das Universidades}

Primeiramente, faz-se necessário determinar de forma ampla conceito de "universidade" bem como o seu progresso no decorrer da história. Marcovitch (1998 apud MACHADO, 2002) lembra que na universidade coexistem inúmeros campos do conhecimento, como também, o compromisso com a formação dos cidadãos. Conforme Grillo (1996 apud MACHADO, 2002), a universidade é uma organização complicada e com finalidades diversas e particularizadas, voltadas para a concepção e propagação do saber. Schuch Jr. (1995 apud MACHADO, 2002), faz referência à universidade como uma organização cuja especificidade provém das peculiaridades da sua condição funcional, que é composta por profissionais altamente competentes, que desempenham suas atividades com autonomia, em um ambiente com grande capacidade criadora e interdependente, que dificulta qualquer tentativa de supervisão direta.

Numa visão mais tradicional, Machado (2002) complementa que a universidade representa a ação nas diversas áreas do conhecimento, dando grande importância ao tripé decorrente das inter-relações entre ensino, pesquisa e extensão. O autor complementa que a universidade é uma organização complexa que pode ser caracterizada, conforme o Quadro 1, abaixo especificado: 
- Pela ambigüidade de objetivos, mesmo quando os objetivos formais normalmente girem em torno da geração e disseminação do conhecimento baseado no tripé do ensino, pesquisa e extensão.

- Por um núcleo operacional altamente profissionalizado.

- Por decisão colegiada que torna o processo decisório mais lento e conflituoso.

- Pelo elevado grau de diversificação horizontal, baseado na diversidade de áreas do conhecimento

- Por um processo produtivo que envolve pessoas e não insumos.

- Por uma forte ação política presente nas diversas coalizões internas decorrentes, principalmente, do processo eletivo para preenchimento de postos gerenciais, geralmente, com participação da comunidade acadêmica.

Quadro 1 - Caracterização da Universidade como uma organização complexa

FONTE: Machado (2002, p. 94)

No entanto, Alperstedt, Martignago e Fiates (2006) gerir uma organização complexa como a universidade demanda cautela a uma série de elementos os quais freqüentemente, pelo grande número de influência mútua existentes, tornam-se incontroláveis. Além de todas as forças que usualmente comprometem as demais organizações, as universidades derivam de problemas decorrentes do próprio alargamento do ensino superior e da interferência normativa do governo, tanto na sua organização quanto no seu funcionamento.

\subsubsection{A procedência e o desenvolvimento das universidades no mundo}

As universidades, conforme Wanderley (1983 apud SILVEIRA, 2006, p. 17), "são herdeiras das instituições formadas no mundo greco-romano, sendo o seu desenvolvimento influenciado pela religião, tanto no oriente islâmico quanto no ocidente cristão".

A origem das universidades assinala para uma das mais antigas, expressivas e marcantes instituições da sociedade. A universidade teve origem na metade do século XII, vinculada a um extenso processo cultural onde em seu começo, as escolas tiveram um aprimoramento impetuoso, os mestres e estudantes emanavam de todas as partes, dando-lhes um caráter internacional (SILVEIRA, 2006).

Na concepção de Verger (1990), o impetuoso surgimento de escolas ocasionou gravíssimos problemas de organização, trazendo como consequiência o reexame das instituições e, por conseguinte, dando origem ao aparecimento das universidades.

Na Idade Média, sua aparição se deu nas principais cidades da Europa, alargandose, em seguida, por todos os continentes. De acordo com autores como Verger (1990) e Wanderley (1983 apud SILVEIRA, 2006), as universidades medievais multiplicaram-se ligeiramente, passando a desempenhar influência simbólica à sociedade envolvida com o saber. Há autores como Peixoto (2000 apud SILVEIRA, 2006) que faz referência, ao mesmo tempo, que tais universidades instituíram-se num mundo ilustrado e que simulavam a forma mais elevada do saber intelectivo. 
A universidade é em alto grau mais do que a simples classificação do status educativo de um sujeito, consiste em, antes de tudo, uma instituição igualitária, cuja função essencial é "formar a elite intelectual e científica da sociedade a que serve" (COLOSSI, 2000 apud SILVEIRA, 2006, p. 18).

Ultimamente, encontrar uma conceituação para a universidade, não é uma empreitada simples onde o mais comum é encontrar conceitos gerais para a universidade, como o de Teixeira (1998) que crê que "a universidade é, em essência, a reunião entre os que sabem e os que desejam aprender" ou como o autor abaixo que versa de sua construção institucional, afirmando que ela

Compreende uma coletividade - na qual se inserem docentes-cientistas, discentes e técnico-administrativos - com uma fronteira relativamente identificável, uma ordem normativa, escalas de autoridade e sistemas de comunicações, e se engaja em atividades que estão relacionadas com um conjunto de objetivos bem definidos. (TRIGUEIRO, 1999, p. 31)

Buscando o dicionário Aurélio, o conceito de universidade é tido como:

Instituição de ensino superior que compreende um conjunto de faculdades ou escolas para a especialização profissional e científica e tem por função precípua garantir a conservação e o progresso nos diversos ramos do conhecimento, pelo ensino e pela pesquisa. (DICIONÁRIO AURÉLIO ELETRONICO - SÉCULO XXI).

Esse conceito se abre, envolvendo, desde suas instalações físicas nas quais funciona até as pessoas, ou seja, corpo docente, corpo discente e pessoal administrativo da universidade.

\subsubsection{O surgimento, a concepção e a evolução das universidades brasileiras}

A origem do ensino superior no Brasil é assinalada durante a permanência da família real na então colônia portuguesa (1808 a 1821). A primeira escola foi criada na Bahia em fevereiro de 1808, com o curso de Cirurgia, Anatomia e Obstetrícia, quando a família real portuguesa chegava ao Brasil. A seguir foi criada a Escola do Rio de Janeiro, com os cursos de Cirurgia, Academia Militar, de Belas Artes, bem como a criação do Museu e Biblioteca Nacional e o Jardim Botânico (MACHADO, 2002).

Existem outras fontes que assinalam a origem do ensino no Brasil com a existência de escolas de preceitos católicos, elitista, voltada para a construção do clero onde os colonizadores constituíram colégios para oferecer educação às elites do País e para dar catequese aos grupos mais pobres (SILVEIRA, 2006). O autor complementa que os primeiros cursos superiores criados no Brasil no início no século XIX, com a chegada de D. João VI, foram os Cursos de Engenharia, Direito e Medicina. 
Em 1920, a primeira universidade formalmente reconhecida pelo governo federal foi instalada no Rio de Janeiro (MACHADO, 2002) e, posteriormente, denominada Universidade do Brasil. Neste período, o Brasil já contava com 41 universidades públicas e mais de 20 privadas onde após, esse período o ensino privado teve sua expansão atingindo em 1970 mais de $70 \%$ dos alunos de nível superior (SCHLEMPER, 1989 apud SILVEIRA, 2006).

Segundo Machado (2002):

A partir do regime militar, ocorreu o fenômeno dos "excedentes". Os excedentes eram alunos que foram aprovados nos vestibulares, mas para os quais não havia vagas nas universidades. Isso gerou uma campanha de pressão que levou o governo militar a dar início ao processo de privatização do ensino superior.

$\mathrm{O}$ autor complementa que em meio a esse processo de privatização do ensino superior, ocorreu a reforma universitária de 1968, materializada no texto da lei 5.540/68 que fixou as normas de organização e funcionamento das universidades públicas brasileiras, adotada também pelas universidades privadas.

Schlemper (1989 apud SILVEIRA, 2006) conclui que em 1986, o Brasil contava com 35 Universidades Federais, 11 estaduais e 5 municipais, totalizando 51 universidades públicas, e 31 particulares, das quais 17 confessionais, todas filiadas ao Conselho de Reitores das Universidades Brasileiras.

Na concepção de Silveira (2006), o aprimoramento do cidadão e, por conseguinte, da nação, bem como a melhoria da qualidade de vida da sociedade, são resultado direto dos índices e níveis gerais de educação em um país. Assim sendo, a universidade tem a missão, desde a sua origem, de gerar, conservar, transmitir e ritualizar uma herança cultural de conhecimentos, idéias e valores que promovem o desenvolvimento da sociedade humana.

Assim sendo, a função social da universidade constituiu-se em um dos fundamentais assuntos da contemporaneidade, na opinião de Martins Filho (1997 apud SILVEIRA, 2006), demandando o contínuo debate das universidades públicas a cerca de sua missão e seu compromisso frente ao novo milênio, ao financiamento e ao aprimoramento educacional em um mundo globalizado.

Todavia, no Brasil diversas das universidades públicas são possuidoras de marcas históricas e de diversificadas conquistas. Essas universidades são a origem do ensino superior brasileiro e as grandes responsáveis pelas pesquisas desenvolvidas no país. Contudo, as universidades públicas coexistem com muitos problemas. Muitos desses problemas estão vinculados à ausência de financiamento para o ensino superior por parte do governo. Outras dificuldades são internas, tais como a complexidade de sua estrutura, a inércia organizacional, 
total dependência econômica do Estado, corporativismo, precário sistema de avaliação dos resultados, currículos extensos e manutenção de cursos de baixa demanda (ALPERSTEDT, MARTIGNAGO E FIATES, 2006).

\subsection{A Universidade de Brasília - locus do estudo}

Para modelarmos a gestão dos ciclos de manutenção de equipamentos é importante conhecermos a estrutura da Universidade de Brasília e como a gestão da manutenção está inserida num cenário construído por: políticas e diretrizes institucionais; estrutura organizacional da $\mathrm{UnB}$ onde seus Centros de Custo desenvolvem atividades diversificadas; política de recursos humanos envolvendo servidores públicos e terceirizados; despesas orçamentárias para manutenção e obras; e crescimento físico constante da instituição.

A Universidade de Brasília (UnB) é uma das mais importantes instituições de ensino superior do Brasil. Fundada em 1962, seu campus principal está localizado na área central da capital do país e ocupa 395 hectares. É constituída de 25 institutos e faculdades, 25 centros de pesquisa especializados e 1,4 mil docentes.

Segundo a UnB possui mais de 28 mil estudantes, em 72 cursos de graduação, sendo 16 noturnos e dois à distância, divididos em quatro campi espalhados pelo Distrito Federal: Plano Piloto, Planaltina, Ceilândia e Gama.

O ensino, a pesquisa e a extensão desenvolvem-se de forma integrada, influenciando o processo de formação dos estudantes e a produção do conhecimento. As 63 opções de mestrado e as 44 de doutorado reúnem 4,5 mil alunos de pós-graduação. Os pesquisadores da UnB dispõem de 400 laboratórios, Hospital Universitário, dois hospitais veterinários, Biblioteca Central, Editora UnB, Centro de Informática, além da Fazenda Água Limpa, cuja área é de cerca de quatro mil hectares.

\subsubsection{Histórico da Universidade de Brasília}

A cidade de Brasília tinha apenas dois anos quando ganhou oficialmente sua universidade federal. Inaugurada em 21 de abril de 1962, a Universidade de Brasília (UnB) funcionava desde o início daquele mês, no Ministério da Saúde. O dia 9 de abril marcou o começo das aulas para os 413 alunos que haviam prestado o primeiro vestibular e, com ele, o da própria instituição que viria a se tornar uma das mais bem conceituadas do Brasil. 
Trilhar esse caminho, no entanto, demandou esforços. Apesar de o projeto original de Brasília, de Oscar Niemeyer e Lucio Costa, já previsse um espaço para a UnB - entre a Asa Norte e o Lago Paranoá, a luta pela construção foi grande. Tudo por causa da proximidade com o Palácio do Planalto, o Congresso Nacional e a própria Esplanada. Algumas autoridades não queriam que estudantes interferissem na vida política da cidade. Finalmente, depois de negociações intensas, em 15 de dezembro de 1961, o então presidente da República João Goulart sancionou a lei 3.998, que autorizou a criação da universidade.

O antropólogo Darcy Ribeiro, idealizador, fundador e primeiro reitor da UnB, sonhava com uma instituição voltada para as transformações - diferente do modelo tradicional criado na década de 1930. No Brasil, foi a primeira a ser dividida em institutos centrais e faculdades.

A Universidade de Brasília (UnB) foi inaugurada em 21 de abril de 1962, com apenas 13 mil metros quadrados de área construída, distribuídos em nove prédios. A primeira instituição do Brasil dividida em institutos centrais e faculdades que criou os cursos-troncos, nos quais os alunos tinham uma formação básica e, depois de dois anos, estudavam as matérias específicas. A UnB é uma das instituições mais bem conceituadas do Brasil. Criou cursos noturnos, inovou com o Programa de Avaliação Seriada (PAS) e adotou o sistema de cotas para negros, que reserva $20 \%$ das vagas para esses estudantes.

Em paralelo ao amadurecimento acadêmico, a UnB foi espaço para muitos fatos políticos importantes. Antes do golpe militar em 1964, por exemplo, a instituição já era tida por setores conservadores como um foco do pensamento esquerdista. A Linha do Tempo mostra esses e muitos outros detalhes da criação, evolução e da vida acadêmica da instituição. A navegação é separada por décadas e alguns eventos contêm fotos dos momentos mais relevantes. O material é atualizado com freqüência e serve como uma referência histórica prática e acessível a todos.

\subsection{Definição de Estratégia}

"Estratégia é uma palavra de origem grega. Strategus, para os gregos antigos significava o general superior, ou generalíssimo e strategia significava a arte deste general" (ALBUQUERQUE, 1983 apud CAPETTI, 2005, p. 27).

São numerosos os julgamentos de estratégia encontrados na literatura. Ansoff (1965 apud RONDON, 2004) conceitua estratégia como algo que faz parte da relação existente entre empresa e seu meio. O próprio autor anos após define estratégia como um 
conjugado de regulamentos de tomada de decisão para guiar a atuação de uma organização (ANSOFF, 1993 apud RONDON, 2004) assim como a concepção de Grant (apud BASTOS; MACEDO-SOARES, 2007) que vêem a estratégia como um assunto unificador que fornece subsídios às ações e decisões de uma organização, de forma a alavancar e alocar os recursos e competências necessários para melhorar e sustentar o desempenho (MACEDO-SOARES, 2000 apud BASTOS; MACEDO-SOARES, 2007).

Lobato (1997 apud RONDON, 2004) conceitua estratégia como um rumo, constituído para vislumbrar os fins organizacionais e cumpri-los de maneira eficaz.

No entanto, a definição de estratégia é relativamente nova no campo da administração, e restringindo-se até bem pouco tempo, ao serviço militar ao servir para indicar a papel administrativo dos generais onde quem exercia o papel de estrategista era o comandante militar ao estabelecer e esquematizar as manobras indispensáveis ao atingimento das metas destinadas a uma finalidade específica (MOTTA, 1991). Porém, o uso da estratégia já estava presente nos escritos de Sun Tzu sobre a arte da guerra, cerca de 2.500 a.C. Contudo, foi com Alexandre "O Grande" da Macedônia, em 334 a.C, que o conceito começou a tomar forma, tendo em vista que, a partir de condições avaliadas como desfavoráveis, conseguiu construir um grande império, vencendo batalhas planejadas e executadas segundo futuros alternativos predeterminados (MACHADO, 2002), ou seja, é apontado que as manobras estratégicas significam optar por caminhos mais vantajosos.

No meio empresarial, foi após a Segunda Guerra Mundial que a estratégia ganhou força, em função da necessidade de pensar as organizações com a perspectiva de futuro, para conhecer e desenvolver possibilidades de melhoria do desempenho e criar condições para a expansão. Na década de 60 o conceito de estratégia se popularizou ao estar associada à função de planejamento. Todavia, o estudo sobre estratégia evoluiu muito, levando em consideração diversos aspectos presentes no ambiente e no momento histórico da organização. Isso tornou possível entender à estratégia por meio de diferentes e complementares definições.

$\mathrm{O}$ conceito de estratégia incorporou-se à administração na metade dos anos 50, devido à insuficiência das ferramentas que eram utilizadas no mercado e a conseqüente desaceleração do aumento da economia (BULGACOV, 1998). Nos anos 60, com o avanço da concorrência, as organizações passaram buscar novas alternativas de gestão, aliando o entendimento de estratégia ao planejamento, dando origem ao planejamento estratégico (KAY, 1996 apud BOTH, 2000). Assim como, Chandler Jr. (1962 apud ROCHA, 1999, p. 11), estratégia pode ser definida como a determinação das metas e objetivos básicos de longo 
prazo de uma empresa, e a adoção de cursos de ação e alocação de recursos necessários para pôr em prática essas metas. (CHANDLER Jr., 1962 apud ROCHA, 1999, p. 11)

“A estratégia é o que a empresa decide fazer, considerando o ambiente, para atingir os objetivos, respeitando os princípios, de acordo com as políticas estabelecidas, visando cumprir a missão no Negócio" (MARCELINO; LIRA, 1999, p. 21) onde, o referido conceito é complementado pela definição de estratégia na visão de Marcovitch:

\begin{abstract}
A estratégia como uma série de diretrizes administrativas que especificam a posição da organização no seu ambiente; as direções em que esta procura crescer e mudar; os instrumentos competitivos que emprega; os meios pelos quais penetrará nos novos mercados; a maneira pela qual levantará os recursos de que necessitar; os pontos fortes que procurará explorar e, inversamente, as fraquezas que procurará evitar. Note-se que a estratégia adotada por uma organização decorre da análise do seu ecossistema. (MARCOVITCH, 1978 apud ROCHA, 1999, p. 14)
\end{abstract}

Autores como Mintzberg (1995 apud BOTH, 2000, p.15), define "a estratégia pode ser vista como o impulso mediador entre organização e seu ambiente". Complementa o autor, que as estratégias podem ser determinadas em termos de planos, padrões, posição e perspectiva. Dito de outra forma, a estratégia é tida como um plano, diz respeito aos padrões de conduta de uma organização entendida como uma posição relacionada à deliberação de um determinado produto ou serviço. Já como perspectiva, seria a visão de futuro de uma organização.

Para a construção de uma boa estratégia faz-se necessário um planejamento. Nesse sentido, o planejamento estratégico é um método eficaz e interativo para determinação de objetivos, políticas e estratégias (presentes e futuras) dos papéis empresariais ou organizacionais e das metodologias das organizações. Sendo preparado por meiopor meio da realização do diagnóstico institucional ao fazer uma análise do ambiente interno e externo à organização dando subsídios aos gestores na tomada de decisão (MINTZBERG; QUINN, 2001 apud REZENDE, 2003).

Para Machado (2002, p. 95),

A "formação de estratégia no ambiente universitário" se configura em um dos mais importantes artigos do gênero e influenciou diversos pesquisadores. Os autores iniciam argumentando que as estratégias adotadas em universidades tanto podem ser deliberadas como emergentes. Na universidade a estratégia é muito mais do que uma prévia articulação de propósitos, ela resulta das ações e decisões que emergem na organização.

Segundo Rocha (1999) a definição de gestão estratégica é mais abrangente do que o planejamento estratégico: este é um processo que tem início, meio e fim, sendo seu produto final o plano estratégico; aquela é um processo ininterrupto e caracteriza-se por uma conduta dos gestores: sua tomada de decisões e ações. Complementa o autor, que o seu 
principal objetivo é idealizar, aprimorar, analisar, programar, monitorar e amparar estratégias que garantam vantagem competitiva à organização.

A gestão estratégica, na concepção de Rondon (2004), é um método ininterrupto, no qual a formulação abrange uma etapa de reflexão, podendo ser formalizado ou subentendido e a prática é a estratégia em ação, a finalidade convertendo-se em resultado.

Na concepção de Moraes (2004) o aumento da competitividade e a necessidade das empresas em apresentar bons resultados constantemente bem como a grande influência da globalização, têm levado as empresas a procurarem padrões de gerenciamento fundamentados em conceitos de racionalização por meio da simplificação do trabalho em busca da redução de custos. Esta busca se torna ainda mais eficaz quando incorporada a uma adequada estratégia empresarial.

Dentro dessa visão, há expressivas mudanças atribuídas às organizações especializadas em serviços como o de manutenção, Crhistopher (1997) salienta que uma das maiores dificuldades estratégicas que as organizações se deparam ultimamente talvez o da logística seja o mais desafiador.

\subsection{Planejamento Estratégico}

Para Melleiro, Tronchin e Ciampone (2005) o planejamento estratégico pode ser entendido como um importante instrumento que traz benefícios na probabilidade de poder fazer escolhas e a elaboração de planos que auxiliam a enfrentar os processos de mudança. Assim, compreende um conjunto de conhecimentos teóricos e práticos ordenados de modo a possibilitar a interação com a realidade, programar as estratégias e as ações necessárias, para alcançar os objetivos e as metas preestabelecidas.

Em outras palavras, pode-se dizer que o planejamento estratégico é "um processo no qual a instituição define seu futuro desejado e formas efetivas de fazê-lo acontecer" (ANSOFF, 1970 apud REBELO; ALMEIDA, 2008, p. 6).

Catelli et al. (1998 apud ROCHA, 1999) distinguem o planejamento estratégico como uma etapa do processo de gestão que tem início com o estabelecimento de panoramas, considera um diagnóstico institucional cujo produto final é um conjugado de diretrizes estratégicas de modo qualitativo que tem como meta garantir a realização da missão e a continuação da entidade.

Por constituir-se numa ferramenta gerencial, o planejamento estratégico passa a ter um papel extremamente importante na tomada de decisão ao definir o rumo a ser tomado 
pela organização. Já a Gestão estratégica se diferencia do Planejamento estratégico tendo em vista que é tida como a formulação e a prática de planos e ao exercício de atividades arroladas a temas que são de importância essencial, comum ou continuada para a organização como um todo (SHARPLIN, 1985 apud ROCHA, 1999).

\subsection{Conceitos e caracterização dos serviços de manutenção}

A manutenção é uma função empresarial, da qual se espera o controle constante das instalações, assim como o conjunto de trabalho de reparo e revisões necessárias para garantir o funcionamento regular e o bom estado de conservação das instalações produtivas, serviços e instrumentação dos estabelecimentos (BRANCO FILHO, 2000).

Para Moraes (2004) a manutenção passou a ser um mal extremamente necessário e tornou-se parte complementar dos empenhos estratégicos de produtividade das empresas. Pode-se dizer que desde a preocupação exclusiva com a disponibilidade do equipamento à priorização da efetividade do negócio.

O conceito de Manutenção segundo Ferreira (1999, p. 1279), significa “os cuidados técnicos indispensáveis ao funcionamento regular e permanente de motores e máquinas".

Manutenção é atentar para que os sistemas continuem a disposição quando demandados a operar e fazer com que as equipes de manutenção venha trabalhar visando alterar de forma positiva as condições de trabalho, num processo de melhora continuada, quebrando paradigmas e inovando a cada projeto (ALMEIDA; VIDAL, 2001).

De acordo com NBR-5462 (ABNT, 2004), a definição de manutenção é a combinação de ações técnicas, administrativas e de supervisão, com a finalidade de conservar ou recolocar um elemento em uma situação na qual possa exercer um papel exigido, dito de outra forma, fazer o que for necessário para garantir que um equipamento ou máquina atue dentro de condições pequeníssimas de requerimentos e especificações.

Segundo Moraes (2004), Manutenção é o ato de constituir e administrar de maneira continuada e metódica as atuações na busca da eliminação de falhas já ocorridas e potencias dos equipamentos, assegurando durante toda sua vida útil, as características especificadas em projeto. Já na concepção de Branco Filho (1996 apud ALMEIDA; VIDAL, 2001, p. 23) a manutenção é tida com "um conjunto de atividades técnicas e administrativas cuja finalidade é de conservar ou restituir, um determinado item, as condições que lhe permitam realizar sua função". 
No entendimento de Kardec e Nascif (2006 apud LIMA; CASTILHO, 2006, p.7) a manutenção tem como objetivo "garantir a disponibilidade da missão dos equipamentos e instalações de modo a atender um processo de produção ou de serviço, com confiabilidade, segurança, preservação do meio ambiente e custo adequados"

A manutenção é a intervenção importante na totalidade do processo produtivo empresarial e, portanto merece ser posicionada como ação estratégica para cumprimento de metas corporativas (PERES; LIMA, 2008, p. 2), porém, Moraes (2004) apresenta outra característica que ajuda a demonstrar a importância estratégica da Manutenção para as empresas e que pode influenciar na mudança de posicionamento em relação à Manutenção, está ligada ao montante que esse setor da atividade empresarial movimenta no Brasil e no mundo.

Tavares (1999) o objetivo final de um sistema aplicado à manutenção é adequado a elementos que permitam obter aumento de rendimento da empresa, utilização mais eficiente dos recursos de mão-de-obra e material disponíveis, melhoria no desempenho e confiabilidade dos equipamentos. O autor complementa que a uma manutenção de qualidade depende da junção de ações imprescindíveis para um elemento (equipamento, obra ou instalação) seja conservado ou restaurado, de modo a poder ficar de acordo com a condição especificada.

A evolução das formas de manutenção com objetivo do aumento da produtividade e da qualidade ocorre da necessidade de se manter em bom funcionamento em todo e qualquer equipamento, ferramenta ou dispositivo para uso no trabalho (BUENO; DOMINGUES; CORRÊAA, 2005, p. 6). No entanto, para Otani e Machado (2008) a manutenção desempenhada como uma atividade estratégica das organizações é diretamente responsável pela disponibilidade dos ativos, com influência direta no capital dos resultados da empresa.

\subsubsection{Histórico da Manutenção}

De acordo com a Bíblia, em Gênesis - Eclesiastes, a atividade de manutenção é uma especialidade antiga, seguindo a primeira grande civilização (4000 a.C.) e recente no campo científico da Gestão Empresarial (ALMEIDA; VIDAL, 2001). No entanto, a partir da Primeira Guerra Mundial, as indústrias passaram a se preocupar com a necessidade garantir os índices mínimos de eficiência (TAVARES, 1999).

Segundo Galvani (2003), na década de 1930, período que transcorreu a Segunda Guerra Mundial, o termo manutenção ganhou maior importância na linguagem militar e denotava manter, nas unidades de batalha, o efetivo e o material numa condição estável. 
“O surgimento da palavra manutenção na indústria ocorreu em 1950 nos Estados Unidos da América e na França, esse termo está mais ligado à expressão 'conservação'” (MONCHY, 1989 apud QUINELLO; NICOLETTI, 2005, p. 21) onde as indústrias passaram a dar maior importância ao desempenho das máquinas procurando prevenir as falhas. Nessa mesma época, às necessidades que apareceram com o término da segunda guerra mundial e com a evolução da indústria eletrônica e da aviação comercial, as indústrias passaram a se preocupar com a especialização da mão-de-obra dando origem ao aparecimento da Engenharia da Manutenção, que planejava e controlava as atividades de manutenção.

Segundo Siqueira (2006 apud LIMA; CASTILHO, 2006) a modernização industrial, advinda após a segunda guerra mundial, fez com que a disponibilidade e confiabilidade dos equipamentos adquirissem maior valor tornando as ações voltadas para a manutenção mais pró-ativas onde "a principal característica que abrange o período entre a revolução industrial e a segunda guerra era a de uma indústria pouco mecanizada, onde não existia a necessidade de manutenção sistemática" (ALKAIM, 2003 apud PERES; LIMA, 2008, p. 1), ou seja, desde a revolução industrial, o molde de gestão da manutenção vem sofrendo transformações a cada descobrimento de um novo método de manutenção (PERES e LIMA, 2008).

A manutenção das empresas tem sido analisada desde os primórdios dos estudos organizacionais. A revolução industrial acontecida no início do século XIX trouxe a mecanização e com ela a necessidade de manter os equipamentos em condições satisfatórias de funcionamento, entretanto, às manutenções não eram sistematizadas e na sua maioria realizadas pelas próprias equipes de produção (KARDEC; NASCIF, 2001).

Após a propagação dos computadores acontecida nos anos 70, agregou-se a Engenharia de Manutenção critérios de planejamento e controle da manutenção possibilitando o desenvolvimento dos serviços de manutenção ao selecionar e analisar dados a respeito dos motivos de falhas em equipamentos e a revisar os procedimentos de trabalho na busca da eficiência se tornar muito mais fáceis e ao ganharem agilidade, possibilitando a evolução dos processos (GALVANI, 2003).

Galvani (2003) complementa que por volta dos anos 80, após o surgimento dos microcomputadores dotados de linguagens mais simplificadas, as atividades de manutenção ganharam mais agilidade tanto na redução de custos e na eficácia dos produtos e serviços possibilitando o avanço dos procedimentos.

Segundo Dias (2002 apud GALVANI, 2003, p. 41), 
As exigências do mercado têm incentivado as empresas a reverem suas prioridades relativas à manutenção onde essa mudança de atitude é impulsionada pela necessidade de redução de custos, aumento de confiabilidade e de disponibilidade de seus ativos.

Percebe-se que atualmente é o momento para refletir, desenvolver e programar procedimentos e métodos que proporcionem conhecimento e permanência para os negócios por meio dos serviços de manutenção. Entretanto, na situação atual, a manutenção precisa adquirir uma função de amplo valor, muito imprescindível para o sucesso de sua missão, agir como elo entre os campos da Engenharia, Suprimentos (Logística) e todos os outros setores de apoio (GALVANI, 2003).

\subsubsection{A Manutenção como Função Estratégica}

Há um crescente entendimento de que bens e serviços de alta qualidade podem dar a uma organização considerável vantagem competitiva tendo em vista que boa qualidade reduz custo de retrabalho, refugo e devoluções.

Como função estratégica, o desempenho da manutenção influencia diretamente na atuação da empresa. Pasqua e Cavichioli (2001 apud GALVANI, 2003, p. 44) "fazem referência à manutenção como um fator estratégico para a competitividade das empresas"; e para Wyrebski (1998) nas indústrias, a manutenção é um fator que lhe proporciona qualidade, produtividade e competitividade.

Na visão de Ramos (1989 apud ALMEIDA; VIDAL, 2001) a gestão estratégica da manutenção surgiu com a necessidade de uma visão mais proativa, não somente no atendimento a elementos de um sistema propagado, mas também, a sua operacionalização tendo em vista que é necessário prever e reexaminar de maneira sistemática e contínua utilizando-se de subsídios para torná-las alcançáveis.

Para Pinto (1998 apud ALMEIDA; VIDAL, 2001):

A gestão estratégica da manutenção representa a importância de pensar e agir estrategicamente, para que a atividade de manutenção se integre de maneira eficaz ao processo produtivo, contribuindo, efetivamente, para que a empresa caminhe rumo a Excelência Empresarial.

É compreensível que a manutenção tenha um caminho a percorrer no que diz respeito aos processos de geração de valor em longo prazo, pois todas as características atuais do capital organizacional da manutenção são dificuldades existentes no dia a dia da manutenção e que não são tratadas de forma correta (PERES; LIMA, 2008, p. 13).

Neste sentido, a Manutenção representa um importante papel na implementação da estratégia para a obtenção de vantagem competitiva nas organizações como um todo. 
Conforme Pinto (1999 apud TROES, 2007), estrategicamente, a manutenção deve medir qual é a sua contribuição para o lucro da empresa; segurança da instalação e das pessoas; preservação ambiental; e mais do que isto, é preciso que todas as pessoas envolvidas tenham ciência destas informações.

De acordo com Viana (2002 apud TROES, 2007, p. 13) "O impacto do planejamento e controle da manutenção para a saúde de uma empresa é primordial, pois seria impossível um atleta competir com chances de vitória, se o seu organismo estivesse debilitado".

A manutenção industrial cuida dos intramuros de uma companhia e o PCM a organiza e a melhora, se este for eficiente, a companhia terá saúde financeira para existir e colocar seus produtos no mercado, com a qualidade superior e preço competitivo.

Segundo Pinto (1999 apud TROES, 2007 p.14). “A atividade de manutenção precisa deixar de ser apenas eficiente para se tornar eficaz", ou seja, não basta, apenas, reparar o equipamento ou instalação tão rápido quanto possível, mas, principalmente, é preciso manter a função do equipamento disponível para a operação, evitar à falha do equipamento e reduzir os riscos de uma parada de produção não planejada, com isso, a manutenção existe para que não haja manutenção.

Numa visão mais aprofundada, observa-se que o trabalho da manutenção está sendo engrandecido onde, cada vez mais, o pessoal da área precisa estar qualificado e equipado para evitar falhas e não corrigi-las por meio de atuações que, na tentativa de prevenir a acontecimento de falhas, são antecipadas por meio da troca de componentes ou elementos do sistema constituindo assim, a manutenção preventiva que tem como objetivo possibilitar uma redução dos custos referentes às substituições, procurando, de uma melhor forma, atender às necessidades de sistemas diferentes (CAVALCANTE, 2005).

\subsubsection{A importância da logística na Manutenção}

Como sendo um instrumento de gestão de formatação contemporânea, a logística ainda que não seja novidade como uma idéia e bem longe de ser um modismo ou uma porta para a resolução de todos os problemas, é, a exemplo da gestão estratégica e da manutenção, um recurso que se delineia como constante, no decorrer dos próximos anos, necessitando ser ininterruptamente aperfeiçoada (CUNHA, 2003). 
Por definição, é possível verificar que a logística está bem relacionada com a função Manutenção, tendo em vista que todos os recursos humanos e tecnológicos podem ser aperfeiçoados com técnicas de logística. Assim como os recursos materiais podem ter seus estoques e sistema de distribuição racionalizada por meio da logística, todas as atividades pautadas à manutenção podem ser otimizadas sob o ponto de vista de tempo e lugar.

Neste sentido, as definições apresentadas não divergem quanto ao significado da palavra Manutenção como "gerenciamento estratégico", "fornecer melhor condição de rendimento nos serviços" e até mesmo, medidas necessárias para conservação ou permanência de alguma coisa ou de uma situação. Segundo Almeida e Vidal (2001), a manutenção está inserida no grupo de atividades primárias que estão relacionadas com Logística ao visar à redução dos custos e níveis de serviços.

Kardec e Nascif (2001) acreditam que a manutenção tem uma função importante no apoio para manter a logística empresarial, a qual está inteiramente relacionada com a concorrência das organizações. A gestão da manutenção precisa apresentar por princípio um apoio eficaz para alcançar a excelência empresarial tendo em vista que esta função não deve caminhar de maneira isolada do restante das funções da organização.

Conforme visto nos itens anteriores, para alcançar níveis de excelência às empresas precisam atuar com eficácia, e para isso necessitam adequar seus processos de manutenção, logísticos e estratégicos, uma vez que o aprimoramento de um processo seja ele, logístico, de manutenção ou estratégico, implica na redução de custos, ganho de tempo e racionalização dos recursos.

\subsection{Logística: Progresso Conceitual e Aplicações}

A procedência do termo logística vem do grego logistiké, por estar associado à lógica, constituindo uma designação dada na Grécia Antiga a partir da aritmética e da álgebra concernente às quatro operações fundamentais.

Contudo, a significado que mais se aproxima do conceito usado hoje em dia em Administração é a do termo militar de procedência francesa logistique, que conceitua a logística como a aproveitamento método da arte de movimentar exércitos, envolvendo os elementos e adaptações que permitam aplicar os planos militares estratégicos e táticos (TIXIER et al., 1983 apud SILVA, 2000). Relaciona-se, deste modo, com a idealização e cumprimento de projetos táticos, alocação de tropas, materiais, transporte, manutenção e operação de instalações e acessórios destinados a auxiliar o desempenho de uma operação 
militar gerando uma considerável preocupação com os aspectos da logística relacionados com a distribuição dos materiais ou produtos.

Paralelamente ao desenvolvimento dos diversos enfoques dados à logística, do ponto de vista teórico, forma sendo concebidos novos conceitos para defini-la. Esta evolução é apresentada resumidamente no Quadro 2, abaixo especificada:

\begin{tabular}{ll}
\hline Ano & \multicolumn{1}{c}{ DEFINIÇÃO } \\
\hline 1927 & $\begin{array}{l}\text { "Existem dois usos para a palavra distribuição que devem ser claramente diferenciadas... o primeiro } \\
\text { descreve a distribuição física como uma atividade de transporte e estoque; o segundo descreve a } \\
\text { distribuição física como uma atividade de marketing”. (a) }\end{array}$ \\
$\mathbf{1 9 6 7}$ "É um termo empregado na indústria e no comercio para descrever o largo alcance das atividades \\
envolvidas com o movimento eficiente de produtos acabados do final da linha de produção para o \\
consumidor e em alguns casos incluindo a movimentação de matérias-primas de sua fonte ao início \\
da linha de produção. (b) \\
"É a integração de duas ou mais atividades com o propósito de planejar, programar e controlar o fluxo \\
eficiente de matérias-primas, produtos em processo, produtos acabados e respectivas informações, do \\
ponto de origem ao ponto de consumo." (c) \\
"É o processo de planejar, programar e controlar, de maneira eficiente e eficaz, o fluxo e \\
armazenagem de matérias primas, produtos em processo, produtos acabado e respectivas \\
informações, do pondo de origem ao ponto de consumo, com o propósito de atender plenamente às \\
necessidades dos clientes." (d) \\
"É o processo de planejar, programar e controlar, de maneira eficiente e eficaz, o fluxo e \\
armazenagem de bens, serviços e respectivas informações, do ponto de origem ao ponto de consumo, \\
com o propósito de atender plenamente às necessidades dos clientes". (e) \\
"É a parte do processo de gestão da cadeia de suprimentos, que trata do planejamento, implementação \\
e controle eficiente e eficaz do fluxo e armazenagem de bens, serviços e informações relacionadas, do \\
seu ponto de origem até o seu ponto de consumo, de maneira a satisfazer plenamente as necessidades \\
dos clientes." (f).
\end{tabular}

Quadro 2 - Evolução do Conceito de Logística

Fonte: Kent Jr.; Flint, 1997 apud Silva, 2000, p. 19

"A logística é o gerenciamento estratégico da totalidade da cadeia de suprimentos" (ALMEIDA; VIDAL, 2001, p. 122). O autor complementa que a logística tem como missão a inserção de inputs ou de serviços adequados no lugar e no momento certo e na qualidade esperada, ao menor gasto possível. Dito de outra forma, a Logística representa uma inovação na visão empresarial ao demandar a necessidade de uma nova ordenação das coisas que estão voltadas para as atividades necessárias ao deixar produtos e serviços disponíveis aos clientes no momento, local e condições desejadas.

Na concepção de Branco Filho (2000 apud GALVANI, 2003), a logística é definida como aprovisionamento de recursos necessários a cumprimento de qualquer atividade, onde a logística de serviços se caracteriza como as competências adquiridas pela organização no sentido de fornecer ou prover um serviço e facilitar o seu uso.

A logística analisa como a administração pode fornecer melhor condição de rendimento nos serviços de distribuição às diferentes unidades, por meio de planejamento, organização e controle eficazes para as atividades de movimentação e armazenagem que tendem a promover o fluxo de produtos (ALMEIDA; VIDAL, 2001). 
Com base em tantos conceitos, pode-se verificar que "a função da logística é responder por toda a movimentação de materiais, seja no ambiente externo ou no ambiente interno da empresa" (PEREIRA FILHO, 2002). 


\subsection{Gestão Estratégica da Manutenção}

Segundo Marquez e Gupta (2006 apud CARSTENS, 2007) a gestão da manutenção é determinada como todas as atividades gerenciais que definem a manutenção escopos ou precedências, tática, e responsabilidades, e executá-los por meios tais como o planejamento da manutenção, o controle e a supervisão da manutenção, e as diversas melhorias nos métodos incluindo aspectos econômicos na organização.

“O objetivo da manutenção é organizar e gerenciar harmoniosamente os recursos humanos na realização de serviços, utilizando materiais, métodos, ferramentas e técnicas modernas, tendo em vista uma finalidade comum: o lucro" (NEPOMUCENO, 1989 apud CARSTENS, 2007 p. 72).

A gestão da manutenção deveria ser vista como parte da estratégia do negócio. O foco se dá na satisfação do cliente com qualidade e flexibilidade e estes critérios estão ligados diretamente com a disponibilidade e confiabilidade dos processos. Para atingir disponibilidade e confiabilidade precisa mudar a cultura organizacional para perceber a importância desta função crítica que é a manutenção. Desta forma a gestão estratégica da manutenção ocorre se for gerenciada em um processo de melhoria continua (MADU, 2005 apud CAPETTI, 2005).

A estratégia de manutenção tem sido apontada como, o emprego dinâmico das forças da manutenção, como um artifício muito competitivo para o exercício de metas de uma organização (SWAMIDASS; NEWELL, 1987 apud CAPETTI, 2005). Essas referidas forças são desenvolvidas e defendidas por um "padrão de decisão" sugerido por Mintzberg (1978 apud CAPETTI, 2005) e Mintzberg e Waters (1985 apud CAPETTI, 2005), este modelo é o conjugado de alternativas feitas dentro das áreas de decisão. Do mesmo modo, levando em consideração a afirmativa de Slack (2002 apud CAPETTI, 2005, p. 41), que "estratégia é um padrão de decisão", as forças industriais são desenvolvidas e sustentadas por estratégias de manutenção.

Carstens (2007) complementa que a gestão estratégica da manutenção garante a conformidade de modo metódico das ações, assistenciar na acumulação de informações a respeito dos equipamentos e indicadores mais importantes ao processo, emprega as ferramentas de qualidade mais adequadas, e emprega, também, as ferramentas de qualidade mais apropriadas ao setor. Diante do exposto acima, verifica-se, então, a existência de um novo entendimento a cerca da função manutenção, no qual ela deixa de ter uma função apenas reativa e executiva das ações estratégicas e passa a influenciar inteiramente nas demarcações 
estratégicas das organizações. Deste modo, busca-se apresentar a existência de um alinhamento entre a estratégia de negócio e a estratégia de manutenção das organizações, oferecendo grande importância ao arranjo da função manutenção como uma manancial de prerrogativas competitivas.

Entretanto, é importante salientar que a manutenção passa ser fazer parte explicitamente do planejamento estratégico da organização, buscando acelerar convergências na função manutenção (tanto estruturais quanto infra-estruturais), desenvolver novas habilitações e utilizá-las primeiramente que a concorrência (HAYES e WHEELWRIGHT, 1985).

A gestão estratégica da manutenção garante a conformidade sistêmica das ações e causa uma especialização a respeito das informações a cerca dos equipamentos, processos técnicos e de gestão e sobre os métodos de manutenção. (CAPETTI, 2005).

Pinto e Xavier (2003, p. 9), complementam que:

"no cenário atual não existe mais espaço para improvisos e arranjos: competência,
criatividade, flexibilidade, velocidade, cultura de mudança e trabalho em equipe são
as características básicas das empresas que tem a competitividade como razão de ser
de sua sobrevivência. Para as pessoas estas características são essenciais para
garantir a empregabilidade de cada um".

O planejamento e as metas da manutenção são os mais importantes elementos do framework de gestão da manutenção. Estes elementos necessitariam ser estabelecidos para sustentar a estratégia do interesse que compõem o fator crítico de sucesso da organização. A gestão da manutenção careceria, por exemplo, amparar a estratégia com o objetivo fim da organização que se esforça para conseguir baixo custo de produção, flexibilidade ou alta qualidade do produto ou serviço que se dispõe a entregar (JONSSON, 1997 apud CAPETTI, 2005).

Assim sendo, e com base na teoria apresentada, é possível concluir que quando a extensão estratégica é levada em consideração, para assumir decisões que causarão as reivindicações futuras de manutenção da organização, estas necessitariam ingressar no comando de intervenções de manutenção. Determinações de mudança de equipamento e alterações de projeto para alargar a confiabilidade do equipamento e manutenibilidade são exemplos destas atividades. Tem duas séries de procedimentos administrativos introduzidos na função da manutenção. A primeira série versa nos processos administrativos de estabelecer políticas de manutenção, formando objetivos, planejamento, auditoria, e a avaliação de desempenho que concentra à função global. A segunda série está preocupada com 
planejamento técnico e a operação de atividades de manutenção para sistemas técnicos individuais. 


\section{METODOLOGIA}

Neste capítulo será apresentado o método científico que foi utilizado no desenvolvimento da pesquisa. Conforme a literatura, todo trabalho científico precisa estar embasado em métodos para que seus objetivos sejam obtidos e seus resultados sejam aceitos pela comunidade acadêmica. Assim, é necessário que a questão da pesquisa, os métodos e técnicas utilizados, o delineamento da pesquisa, as definições constitutivas e operacionais das categorias de análise, a coleta de dados e forma de análise e as limitações da pesquisa fiquem esclarecidos.

\subsection{Delineamento da pesquisa}

Conforme Gil (1999) e Vergara (2000), a pesquisa pode ser qualificada quanto aos fins e aos meios: Quanto aos fins, a pesquisa foi descritiva por tentar averiguar a influência da área de manutenção de equipamentos no contexto da Gestão Estratégica Universitária. Para Vergara (2000), a pesquisa descritiva deve delinear as peculiaridades de uma dada população ou fenômeno, estabelecendo correlações entre variáveis e definindo sua natureza. Quanto aos meios, a pesquisa é um estudo de caso por ser uma investigação sem caráter científico que busca acontecimentos atuais dentro de um situação de vida real, sobretudo onde as fronteiras entre o fenômeno e o contex to não estão visivelmente determinadas.

No presente trabalho, a pesquisa foi de caráter quantitativo uma vez foram levantadas, por meio de questionários, informações que possam ser relevantes na compreensão e solução do objetivo apresentado.

\subsection{População e Amostra da pesquisa}

Universo de pesquisa ou população, segundo Stevenson (1981), consiste no todo pesquisado, do qual se extrai uma parcela que será examinada e que recebe o nome de amostra. Dito de outra forma, população "é um conjunto definido de elementos que possuem determinadas características" (GIL, 1999, p. 99).

O universo da pesquisa contemplou 136 Centros de Custo da Universidade de Brasília que dispõe atualmente de um quadro de pessoal composto por 2.365 funcionários técnicoadministrativos e 1519 docentes. A amostra, segundo Gil (1999, p. 100), "é o subconjunto do 
universo ou população, por meio do qual se estabelecem ou se estimam as características desse universo ou população".

Esta pesquisa foi do tipo não probabilística associada a formas por acessibilidade e por tipicidade. Conforme Vergara (2000), a acessibilidade caracteriza-se por usar elementos de fácil acesso e tipicidade por especificar a população-alvo onde a amostragem utilizada neste trabalho foi constituída por 92 de servidores/ colaboradores técnico-administrativos, ocupantes de cargos administrativos, ligados diretamente com os serviços de manutenção bem como com o planejamento estratégico da Universidade, ou seja, diretamente relacionados com a gestão e os serviços de manutenção da Universidade.

\subsection{Instrumento da Coleta de Dados}

No primeiro momento, a coleta dos dados foi constituída da técnica de aplicação de questionários elaborado com 10 (dez) questões fechadas e (01) uma questão aberta com o objetivo de captar a percepção dos respondentes em relação aos aspectos dos serviços de manutenção e gestão estratégica da Universidade, em estudo.

As respostas dos itens se deram em uma escala de Likert em que se manifesta a concordância ou discordância do respondente em relação a cada um dos enunciados, segundo a graduação discorda totalmente (1); discorda em parte (2), Não concorda e nem discorda (3), concorda em parte (4), concorda totalmente (5), para variáveis e atitudes relacionadas com o objeto de estudo.

Segundo Gil (1999, p. 146), a escala de Likert "baseia-se na elaboração mais simples e de caráter ordinal, não medindo, portanto, o quanto uma atitude é mais ou menos favorável".

Também foram levantados dados demográficos dos sujeitos da pesquisa, referentes à idade, a sexo, formação acadêmica, nível funcional, tempo de serviço e tipo de vínculo, com vistas à melhor conhecer e caracterizar a amostra e, principalmente, a identificar eventuais diferenças ou correlação entre as características levantadas e as percepções acerca do objeto de estudo.

\subsection{Procedimentos da Coleta de Dados}

Os questionários foram pela pesquisadora e respondidos individualmente. Dessa forma o questionário foi aplicado no período de março a abril de 2009 a 92 pessoas dentro da 
área administrativa da Universidade de Brasília por serem de considerável abrangência do ramo da atividade pesquisada. A abordagem aos servidores/ colaboradores ocorreu de forma cautelosa e educada sendo mantido diálogo com as pessoas no sentido de informar da pesquisa que se pretendia realizar de cunho acadêmico abordando os serviços prestados Gestão Estratégica Universitária e serviços de manutenção.

Foi explicada aos servidores/ colaboradores técnico-administrativos a importância de sua colaboração na coleta dos dados para uma pesquisa acadêmica, bem como foram garantidas a confidencialidade das informações coletadas, com omissão de nomes. Além disso, foi firmado um compromisso em relação o conhecimento do resultado do trabalho quando sua conclusão.

\subsection{Procedimentos de Análise dos Dados}

Para atingir os objetivos propostos nesta pesquisa foi utilizado o Método da Análise descritiva dos dados. Essa análise foi feita por meio do auxílio de uma planilha do MS Excel, com a finalidade de realizar cruzamentos e análise dos dados, com o objetivo de se obter resultados estatísticos no tratamento dos dados tabulados por meio das frequências encontradas nas informações.

O objetivo dessa análise foi de sumarizar as observações após o processamento de dados com condições que permitam obter respostas aos problemas da pesquisa devendo procurar identificar elementos como: caracterizar o que é, ou não, típico no grupo estudado; mostrar outros aspectos da maneira pela qual os indivíduos de distribuem em relação à variável que está sendo medida e a relação entre as diferentes variáveis bem como descrever as diferenças entre dois ou mais grupos de indivíduos. 


\section{APRESENTAÇÃO E DISCUSSÃO DOS RESULTADOS}

Neste capitulo será apresentada a análise e discussão dos resultados da pesquisa, buscando selecionar os aspectos mais significativos que respondem os objetivos deste trabalho: delinear o papel da função manutenção dentro da Gestão Estratégica Universitária; identificar o alinhamento da manutenção com a estratégia da Universidade de Brasília; verificar, no nível perceptivo dos participantes da pesquisa, se os serviços de manutenção podem ser vistos como um fator na redução dos custos.

\subsection{Perfil dos Sujeitos da Pesquisa}

Um dos objetivos deste estudo foi o de traçar o perfil demográfico-funcional dos servidores/ colaboradores da Universidade que atuam na área administrativa que são estão diretamente ligados com as ações estratégicas da Universidade bem como com os serviços de manutenção. No entanto, foi considerado as seguintes variáveis: sexo, idade, escolaridade, nível funcional de atuação, tempo que trabalha na UnB e tipo de vínculo.

Dos 136 questionários distribuídos nos Centros de Custo da Universidade de Brasília, 92 foram devolvidos devidamente preenchidos, ou seja, o equivalente a $68 \%$. Sexo e Faixa etária estão distribuídos de forma diversificada, conforme as tabelas 1 e 2 a seguir:

\begin{tabular}{lc}
\hline Sexo & Quantidade \\
\hline Masculino & 51 \\
Feminino & 36 \\
\hline
\end{tabular}

Tabela 1 - Sexo da População

Fonte: Dados da Pesquisa, 2009

Observa-se na Tabela 1 que 59\% dos respondentes são do sexo masculino e $41 \%$ são do sexo feminino.

\begin{tabular}{lc}
\hline Idade dos Sujeitos da Pesquisa & Quantidade \\
\hline $18-25$ anos & 1 \\
$26-30$ anos & 4 \\
$31-35$ anos & 17 \\
$36-40$ anos & 11 \\
$41-45$ anos & 18 \\
Acima de 46 anos & 36 \\
\hline
\end{tabular}

Tabela 2 - Faixa Etária

Fonte: Dados da Pesquisa, 2009 
Nota-se, na distribuição e frequência que a faixa etária dos respondentes que $41 \%$ tem acima de 46 anos e que $18 \%$ tem entre 36 e 40 anos. Pode-se dizer que esta é uma faixa altamente predominante nos serviços administrativos da Universidade.

Quanto à escolaridade, a amostra constitui-se de diversificados graus, conforme informações constantes na Tabela 3:

\begin{tabular}{lc}
\hline Escolaridade & Quantidade \\
\hline Ensino Básico ou Fundamental & 0 \\
Ensino Médio & 19 \\
Técnico & 21 \\
Graduado & 28 \\
Pós-Graduado & 14 \\
\hline
\end{tabular}

Tabela 3 - Escolaridade

Fonte: Dados da Pesquisa, 2009

No tocante à escolaridade dos respondentes, verifica-se que apenas $22 \%$ concluíram o Ensino Médio se comparado ao restante do grupo pesquisado que chegaram fazer outros cursos bem como $32 \%$ já concluíram o ensino superior.

A Tabela 4 apresenta a distribuição total dos servidores/ colaboradores da UnB que responderam ao questionário, de acordo com suas posições funcionais:

\begin{tabular}{lc}
\hline Nível Funcional & Quantidade \\
\hline Auxiliar & 6 \\
Assistente & 17 \\
Técnico & 47 \\
Supervisão & 21 \\
\hline
\end{tabular}

Tabela 4 - Nível Funcional

Fonte: Dados da Pesquisa, 2009

Quanto ao tempo de trabalho na função, $43 \%$ dos respondentes foram admitidos na Universidade antes de 1978, ou seja, mais de 21 anos de tempo de serviço, conforme Tabela 5.

\begin{tabular}{lc}
\hline Tempo de atuação & Quantidade \\
\hline 0 a 4 anos & 6 \\
5 a 8 anos & 17 \\
9 a 12 anos & 15 \\
13 a 16 anos & 1 \\
17 a 20 anos & 8 \\
Acima de 21 anos & 40 \\
\hline
\end{tabular}

Tabela 5 - Tempo de Atuação na área

Fonte: Dados da Pesquisa, 2009 
Quanto ao tipo de vínculo empregatício, 53\% dos respondentes são funcionários do Quadro Permanente de Pessoal, conforme Tabela 6.

\begin{tabular}{lc}
\hline Tipo de Vínculo Empregatício & Quantidade \\
\hline Servidor do Quadro Permanente & 49 \\
Colaborador Terceirizado & 1 \\
Prestador de Serviços & 13 \\
Estagiário/ Bolsista & 5 \\
\hline
\end{tabular}

Tabela 6 - Vínculo Empregatício

Fonte: Dados da Pesquisa, 2009

Nota-se que 53\% dos respondentes são Servidores do Quadro Permanente da Universidade. Um percentual significativo e relevante de pessoal que trabalha nos Centros de Custos.

Em síntese, pode-se dizer que o perfil demográfico-funcional dos servidores/ colaboradores da Universidade de Brasília que atuam na área administrativa, que há uma considerável predominância, de respondentes que pertencem ao quadro permanente de pessoal da Universidade onde a maioria é do sexo masculino, com uma faixa etária acima de 40 anos de idade e uma média de 20 anos de atuação na Universidade, ocupantes de cargos técnicos e de supervisão como uma formação acadêmica acima do segundo grau.

\subsection{O papel da função manutenção dentro da Gestão Estratégica Universitária;}

Ao resumir o que foi dito na teoria apresentada a respeito do tema manutenção como uma função estratégica, pode-se dizer que a mesma demanda um padrão de gestão que una junto à manutenção as áreas de planejamento, pois estas duas áreas citadas (planejamento e manutenção) são estratégicas para a ampliação das atividades institucionais, e este modelo de gestão deverá estar alinhado aos resultados a serem obtidos pela organização. .

Para análise deste objetivo específico, foi avaliada a visão do grupo no tocante à influência da gestão estratégica da manutenção de equipamentos na redução dos custos e a influência da área de manutenção de equipamentos nas decisões de planejamento estratégico da Universidade onde os Gráficos 1 e 2, respectivamente apresentados a seguir, permitem a visualização desta referida análise: 


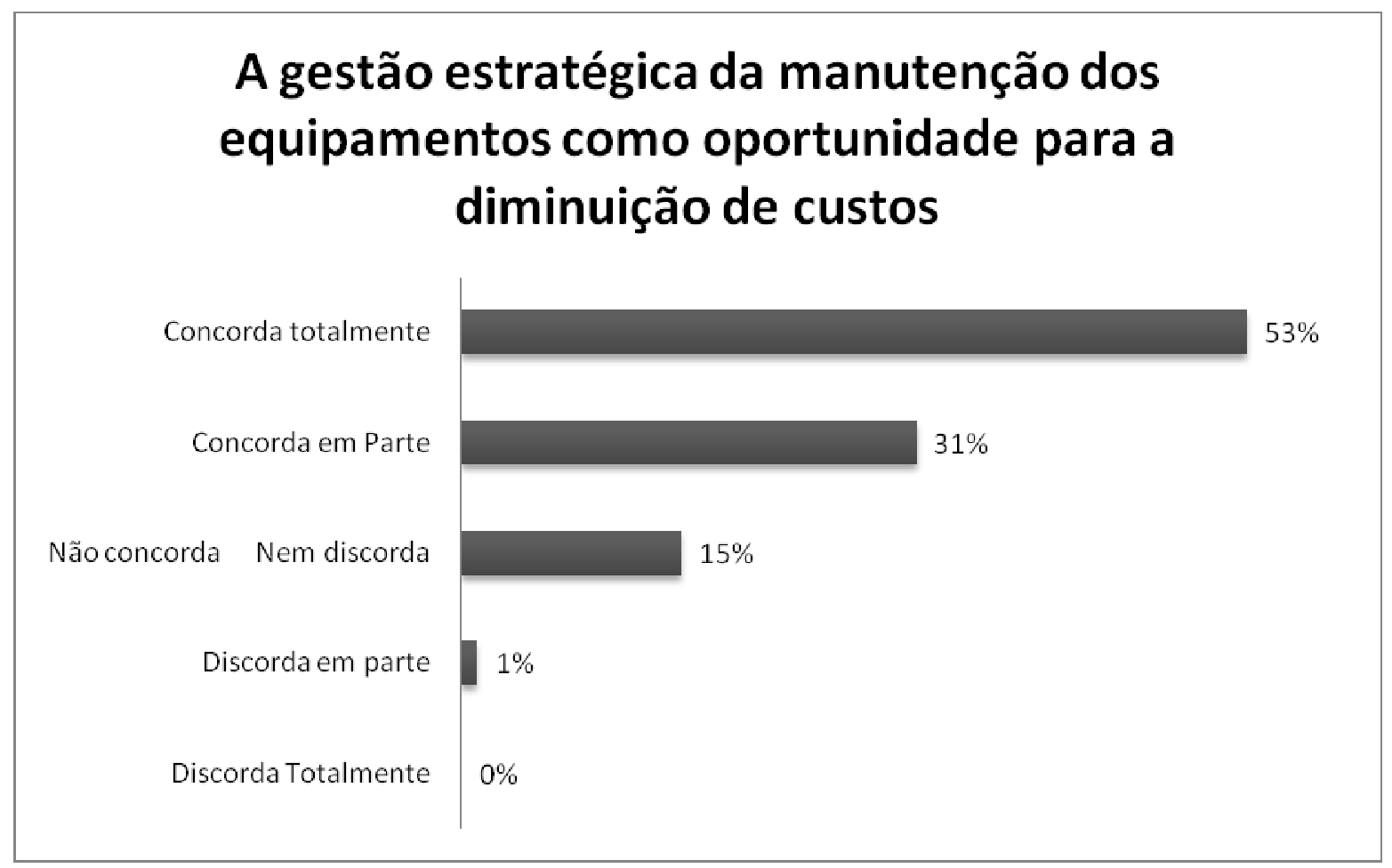

Gráfico 1 - A Gestão Estratégica da Manutenção como oportunidade para redução de custos Fonte: Dados da Pesquisa, 2009

Para análise desta dimensão acerca da influência da gestão estratégica da manutenção de equipamentos na redução dos custos nas atividades exercidas pela UnB, verifica-se uma boa percepção do grupo, uma vez que 53\% concordam totalmente e $31 \%$ concordam em parte que atuações bem sucedidas junto aos serviços de manutenção de equipamentos são capazes de ocasionar em oportunidades de diminuição dos custos.

Foi avaliada a visão do grupo no tocante a influência da área de manutenção e sua contribuição para o processo de formulação de estratégia nas atividades exercidas pela Universidade de Brasília onde o Gráfico 2, a seguir, permite a visualização da contribuição da área de manutenção para o processo de formulação estratégica: 


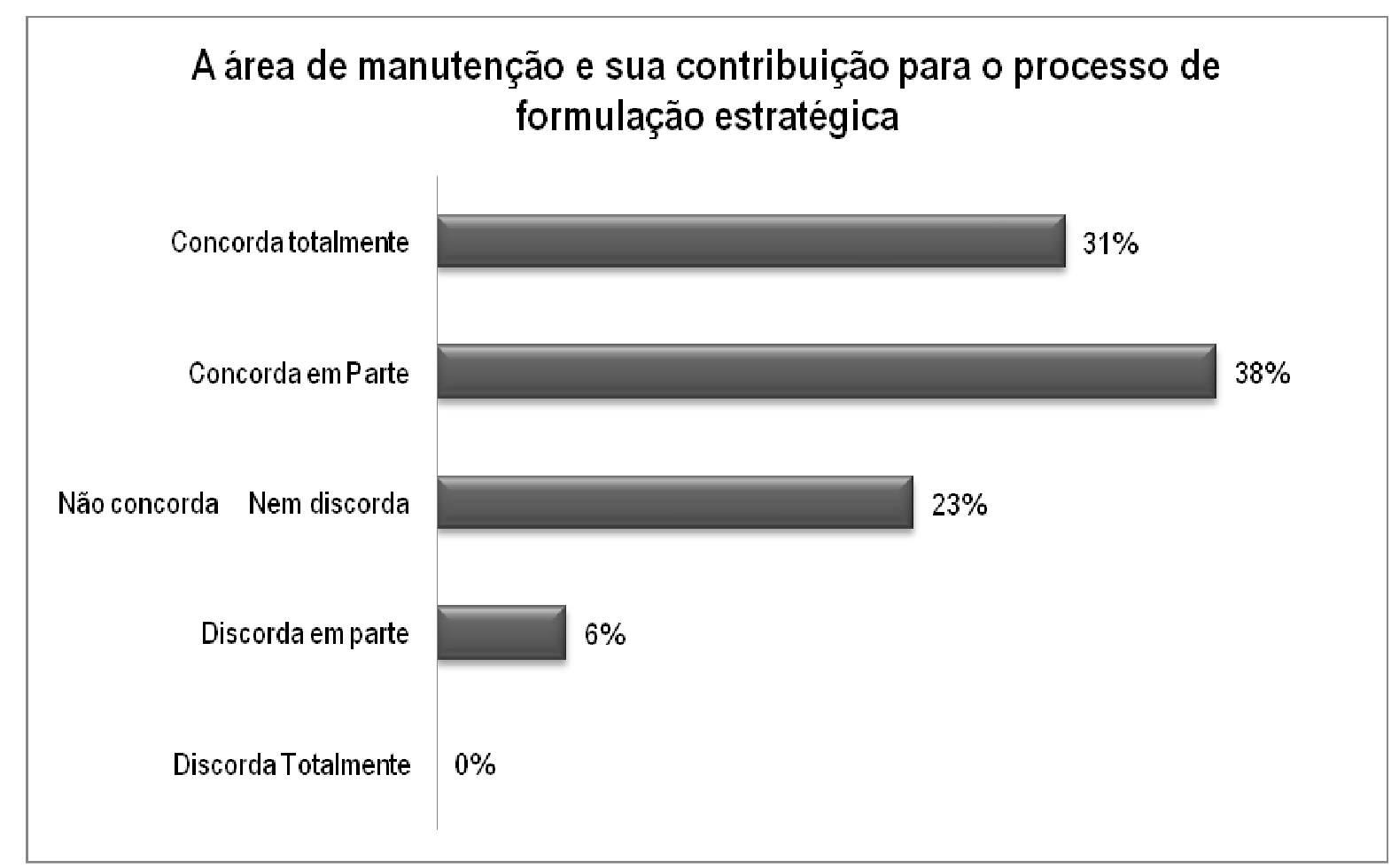

Gráfico 2 - A área de manutenção e sua contribuição para o processo de formulação estratégica Fonte: Dados da Pesquisa, 2009

Na avaliação geral acerca da dimensão acima apresentada demonstra-se uma boa percepção do grupo com relação à importância dos serviços de manutenção, onde $31 \%$ concordam totalmente e $38 \%$ concordam em parte que atuações bem sucedidas juntos aos serviços de manutenção de equipamentos têm influência nas decisões de planejamento da estratégia da Universidade.

Os Gráficos 1 e 2, também legitimam o que é apresentado na teoria onde Pasqua e Cavichioli (2001 apud GALVANI, 2003) fazem referência aos serviços de manutenção serem um fator estratégico para a competitividades das organizações, Wyrebski (1998) que complementa que a manutenção é um fator que pode proporcionar qualidade, boa produtividade, redução de custos e competitividade para as organizações bem como Kardec e Nascif que dão destaque a importância de trabalhar com estratégias de gestão apontando para o abrangência de objetivos estratégicos das organizações.

Os dados corroboram o que é dito na teoria de acordo com os estudos realizados ao apresentar que a manutenção não tem somente uma função reativa e executiva das ações estratégicas, mas sim, uma total influência nos limites estratégicos das organizações como um elemento competitivo para o alcance de resultados, e com este pensamento é possível ampliar um modelo de gestão em conformidade com as estratégias e políticas organizacionais, e por 
sua vez, a operação dos serviços de manutenção poderá ser analisada como função estratégica para a instituição.

\subsection{O alinhamento da manutenção com a estratégia da Universidade de Brasília.}

Para análise desta dimensão, foi avaliada a visão do grupo no tocante ao desempenho da área de manutenção de equipamentos e sua influência nos resultados obtidos pela universidade (Gráfico 3), se a Universidade demanda da área de manutenção a função de sustentar as condições que ela necessita para produzir (Gráfico 5), se a melhoria no desempenho dos equipamentos decorrem de resultado das ações da manutenção junto a Universidade (Gráfico 4).

Os Gráficos 3 e 4 apresentados a seguir, permitem a visualização desta referida análise:

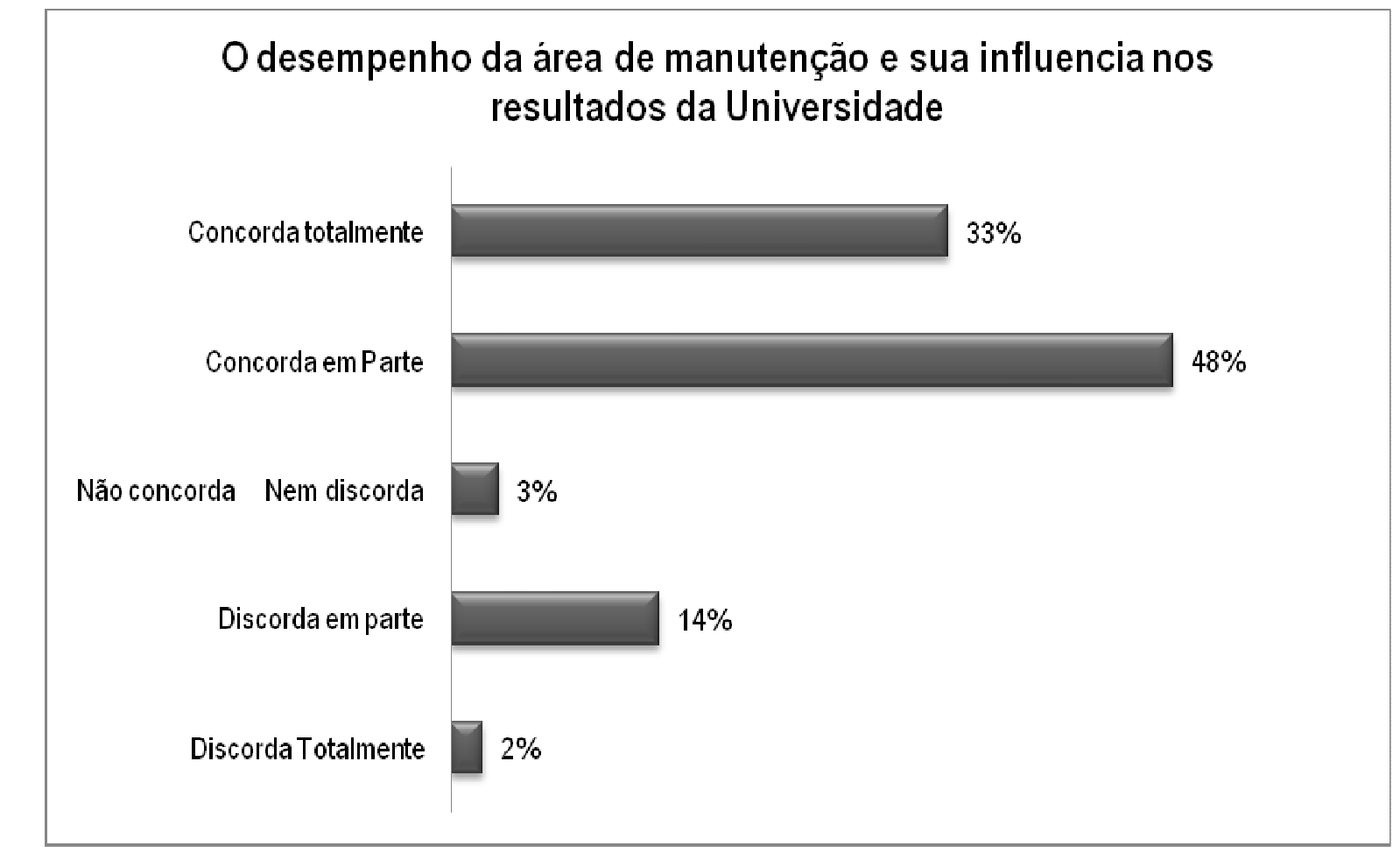

Gráfico 3 - O desempenho da área de manutenção e sua influência nos resultados da Universidade Fonte: Dados da Pesquisa, 2009

Por meio da avaliação no tocante ao desempenho da área de manutenção e sua influência nos resultados da Universidade apresentado no Gráfico 3 é possível verificar que há uma boa percepção do grupo pesquisado em relação à vinculação dos serviços de manutenção à Gestão Universitária onde $33 \%$ concordam totalmente e $48 \%$ concordam em parte com o referido questionamento. 
Na tentativa de complementar as informações apresentadas no Gráfico 3, buscouse analisar a visão geral do grupo pesquisado no tocante ao progresso do desempenho dos equipamento transversalmente às ações de manutenção exercidas junto à Universidade, cuja análise apresentada no Gráfico 4, demonstra uma excelente percepção por parte do grupo pesquisado no que diz respeito a esta abordagem onde $45 \%$ concordam totalmente e $48 \%$ concordam em parte que melhorias na atuação da área de manutenção são influenciadas por ações estratégicas da Universidade.

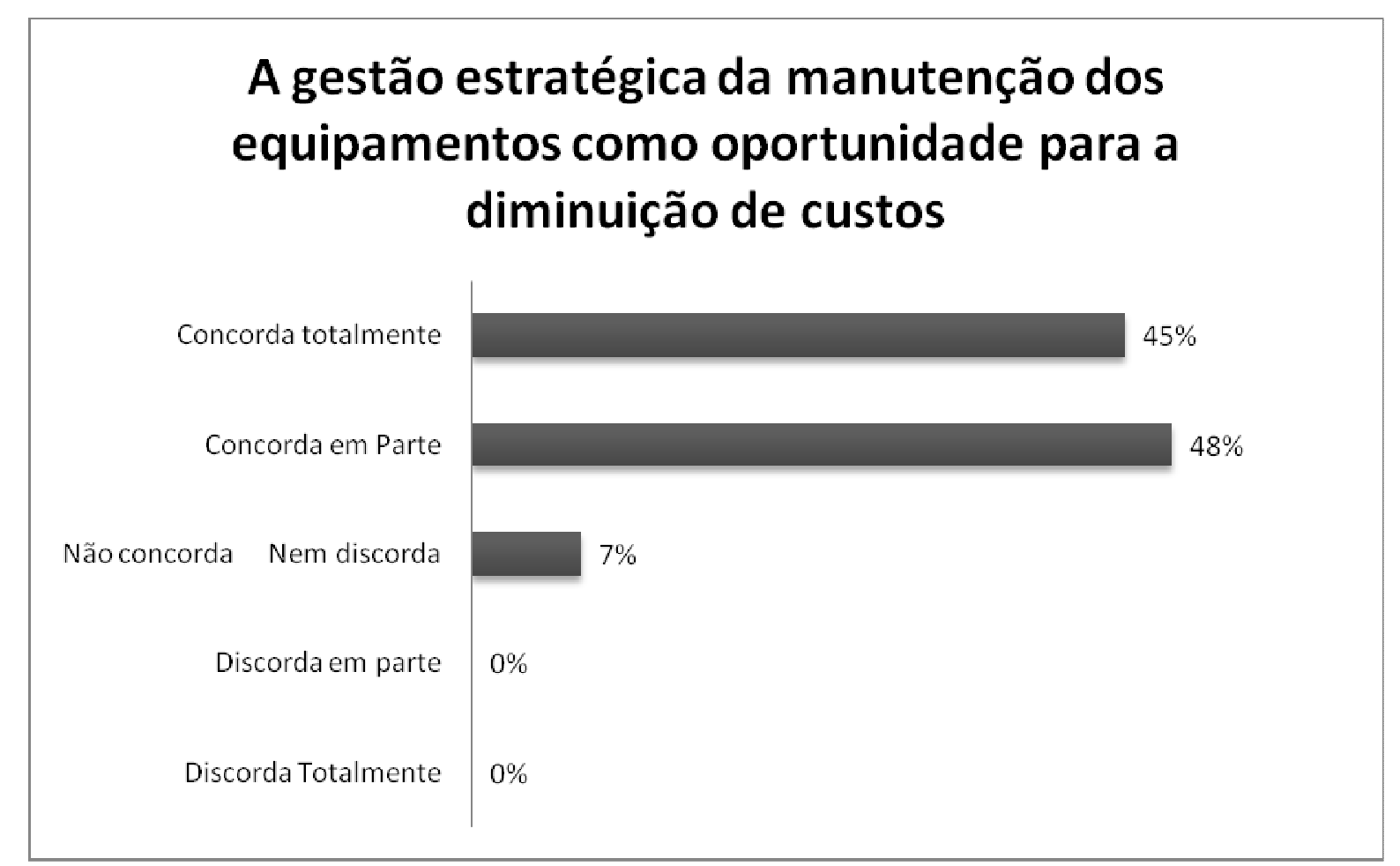

Gráfico 4 - O desempenho dos equipamentos e as ações da manutenção junto à Universidade Fonte: Dados da Pesquisa, 2009

Os Gráficos 3 e 4, reafirmam o que é apresentado na teoria por meio dos estudos de Hayes e Wheelwrigh (1985) ao salientar que os serviços de manutenção fazem parte explícita do planejamento estratégico das organizações, pois buscam acelerar convergências na função manutenção ao desenvolver novas habilidades bem como os estudos de Pinto e Xavier (2003) que apresentam os serviços de manutenção como um fator estratégico para a competitividade das organizações bem como Wyrebski (1998) que complementa que a manutenção é um fator que pode proporcionar qualidade, boa produtividade, redução de custos e competitividade para as organizações.

Com base no que foi exposto e tomando como referência os gráficos apresentados, observa-se que as afirmações descritas possibilitam concluir que na Universidade de Brasília os serviços de manutenção podem ser fatores influenciadores do 
planejamento estratégico, ao fornecer subsídios para a consecução das metas bem como nas decisões estratégicas.

\subsection{A eficiência na gestão dos serviços de manutenção como um fator redutor de custos na perspectiva dos usuários}

Para análise desta dimensão, foi avaliada a percepção do grupo no tocante à redução de custos por meio de ações bem sucedidas de manutenção (Gráfico 5) bem como se a Universidade investe nos serviços de manutenção com o objetivo de reduzir custos (Gráfico $6)$.

Os Gráficos 5 e 6 apresentados a seguir, permitem a visualização dos dados encontrados.

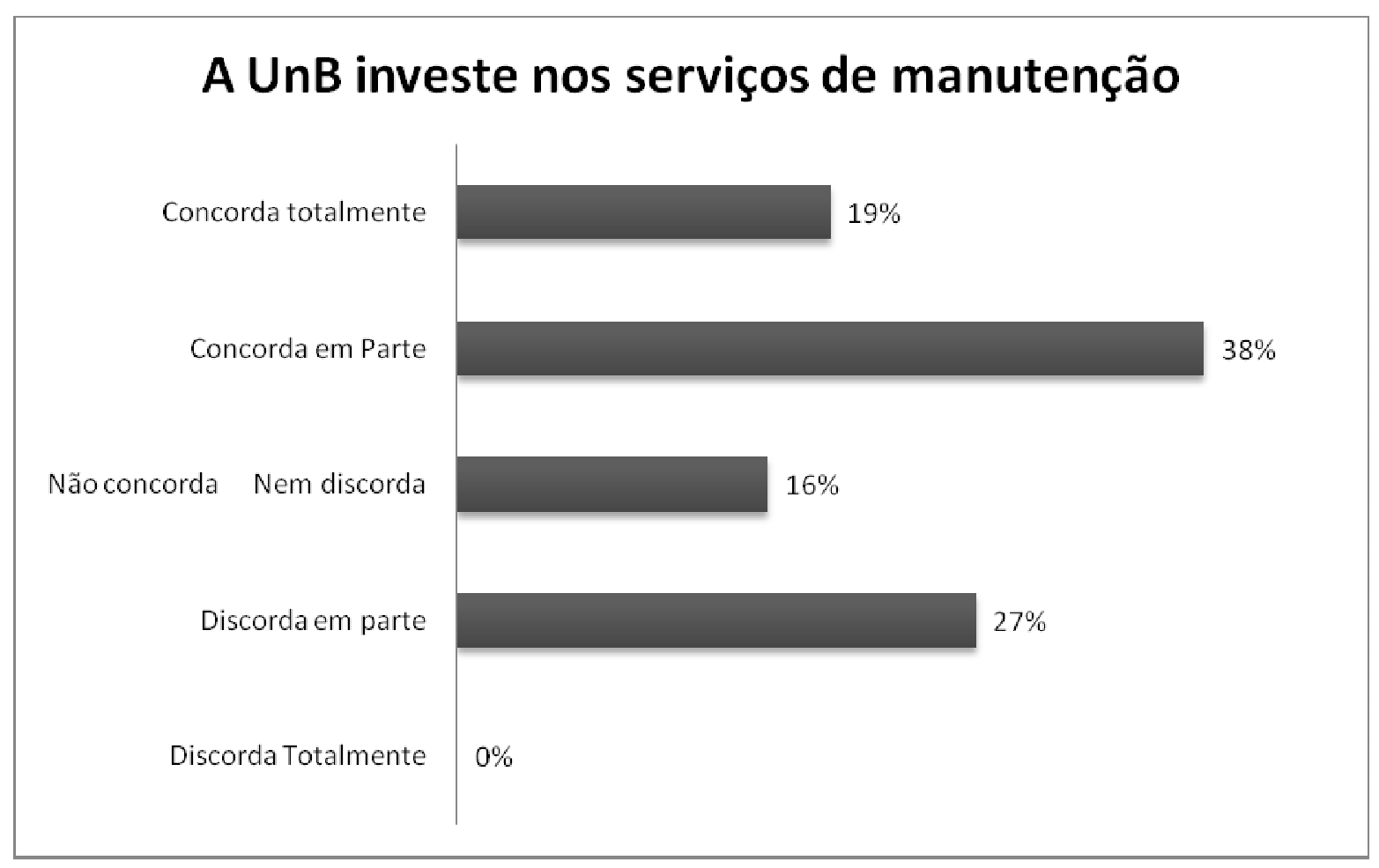

Gráfico 5 - Existência de investimentos com o fim reduzir gastos Fonte: Dados da Pesquisa, 2009

Nota-se que na avaliação concernente aos investimentos da Universidade nos serviços de manutenção é possível verificar que há uma desarmonia de percepções por parte do grupo pesquisado onde $27 \%$ discordam em parte apesar de $19 \%$ concordarem totalmente e $38 \%$ concordarem em parte com o referido questionamento.

O Gráfico 5 apóia o que é apresentado na teoria por meio dos estudos de Moraes (2004) ao salientar que as organizações podem adquirir bons resultados por meio de investimentos em serviços de manutenção com o objetivo de adquirirem mais conceitos de 
racionalização por meio da simplificação do trabalho trazendo como consequência, a redução de custos.

Verificou-se que, na visão dos respondentes desta pesquisa, as inserções de investimentos em serviços de manutenção de equipamentos por parte da Universidade possam reduzir custos e adquirir bons resultados.

As informações apresentadas no Gráfico 6, permitem uma melhor visualização dos resultados onde se percebe uma boa percepção do grupo pesquisado no que diz respeito às ações de manutenção e sua influência na redução de novas aquisições onde $47 \%$ do grupo concorda totalmente e $46 \%$ concordam em parte.

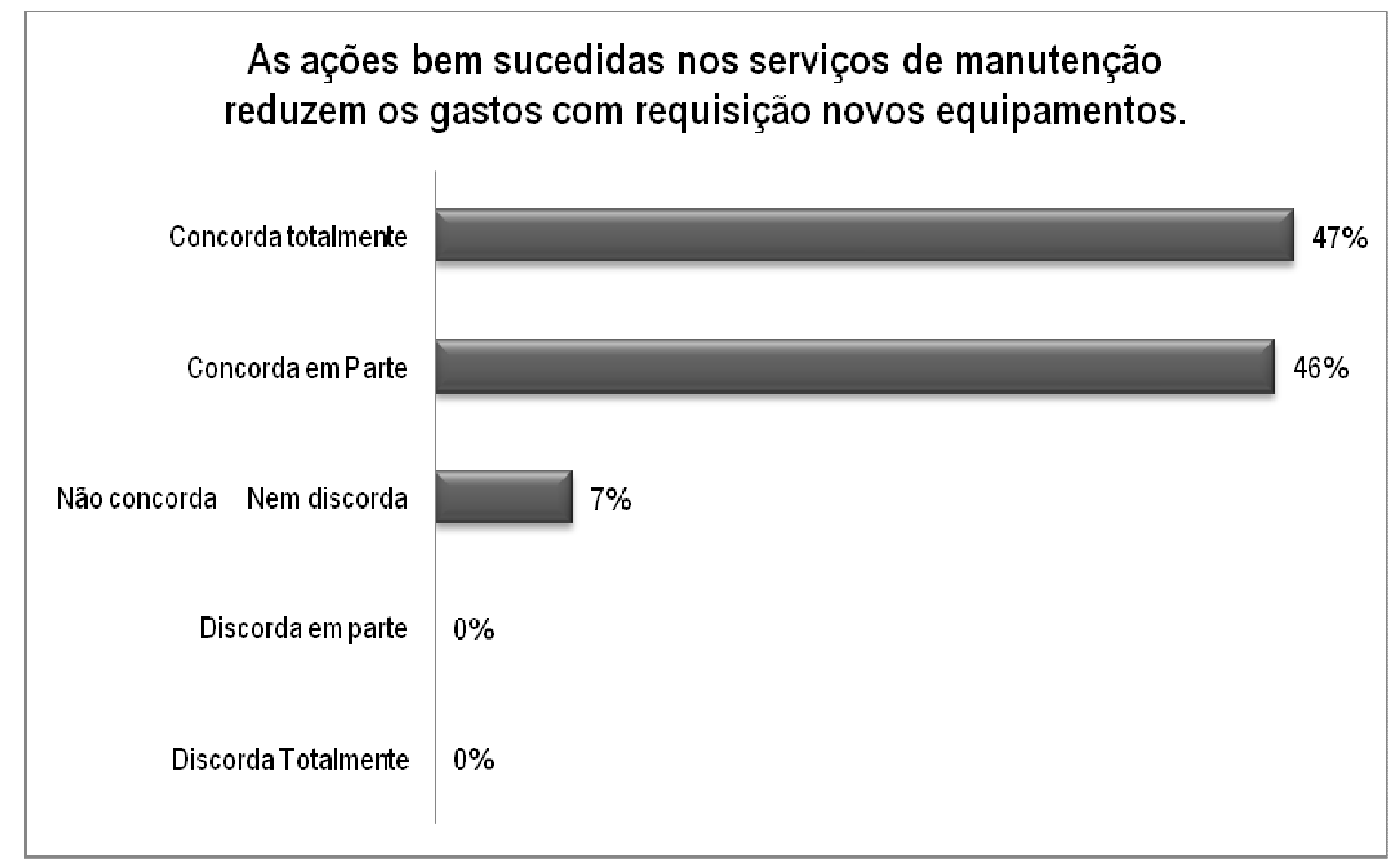

Gráfico 6 - Ações de manutenção reduzem gastos com novas aquisições?

Fonte: Dados da Pesquisa, 2009

A manutenção exerce função de elementar importância dentro das organizações, devido à sua missão que é a de garantir a disponibilidade da função dos equipamentos e instalações de modo atender um programa de produção ou garantir a entrega de um serviço com preservação do meio ambiente, confiabilidade, segurança e custos adequados (PINTO e XAVIER, 2003).

É importante salientar que, conforme a revisão teórica apresentada, a necessidade de melhor alocação de recursos, aumento da receita bem como o aumento da confiabilidade dos equipamentos tem levado as organizações a priorizar investimentos de manutenção, passando a ter uma visão de negócio na ação de manutenção tendo em vista que quanto maior 
for o tempo de vida útil de um determinado equipamento, menor será a necessidade de uma nova aquisição conforme é apresentado no Gráfico 6.

Em termos gerais, a análise dos dados possibilitou identificar que na visão do grupo pesquisado há uma razoável sinergia no que tange à Gestão da Universidade de Brasília e os serviços de manutenção de equipamentos. Esses dados proporcionaram um melhor entendimento a respeito da visão dos usuários dos serviços de manutenção da UnB além de contribuir aos estudos na área de Gestão Estratégica da Manutenção voltada para a área Universitária. Do mesmo modo, constata-se por meio dos dados que as pessoas que fizeram parte da amostra pesquisada consideram a gestão de manutenção essencial para o desempenho da organização. Até porque, a manutenção tem por objetivo garantir o funcionamento dos equipamentos e instalações no transcorrer do tempo de sua utilização e a não degeneração do desempenho. 


\section{CONCLUSÕES}

A estratégia de operações e seus desdobramentos na organização como um todo geram vantagens que dificilmente serão suplantadas. E a área de manutenção contribui significativamente na obtenção dos resultados destas organizações. O que pode ser observado por meio do estudo de caso apresentado, é que na percepção do grupo pesquisado, a consequiência das ações voltadas para o desempenho da atividade da manutenção está inteiramente relacionada com a ligação planejamento/ manutenção.

Conforme foi apresentado no início deste trabalho, a investigação foi desenvolvida com base na seguinte questão:

"Há integração entre as ações da área de manutenção de equipamentos e a formulação e prática de estratégias na Instituição Federal de Ensino Superior estudada?”

Foi possível verificar que embora as finalidades estratégicas de cada instituição possam ser constantemente variáveis, o desempenho da manutenção muda com o mínimo de intensidade e agüenta o controle do posicionamento hierárquico o qual está inserida. Este posicionamento é que define a extensão do papel da manutenção, associado com a importância das determinações munidas pela manutenção.

Como foi observado, apesar de ainda incipiente, existe um alinhamento entre os serviços de manutenção e a Gestão Estratégica Universitária no tocante à gestão da Universidade de Brasília, considerando apenas o nível perceptual de análise dos respondentes da pesquisa.

Nota-se que o desenvolvimento nos serviços de manutenção de equipamentos se mostrou determinante para o melhor aproveitamento das ações nesta área. Consequentemente, este reconhecimento está presente na visão dos usuários destes serviços. Esta constatação confirma os estudos apresentados no capítulo 2, que apontam os serviços de manutenção como uma ferramenta importante para as organizações, pois, por meio dela, é possível reduzir custos, aumentar as disponibilidades dos equipamentos e, por conseguinte, dar continuidade dos serviços prestados pela organização que depende do bom funcionamento de seus equipamentos e sistemas.

Por meio deste estudo foi possível perceber que a área de manutenção trilha um caminho que tem como objetivo a valorização estratégica nas organizações, e a Universidade de Brasília é uma instituição reconhecida, e carece estar modernizando suas atividades e dentre elas está a manutenção, cuja gestão deverá estar sempre se atualizando. Outro ponto 
importante bastante positivo foi encontrado quando se tentou verificar se a manutenção era parte do processo de formulação estratégica da universidade e se constatou que a manutenção confirma sua participação no processo de formulação das estratégias, na perspectiva dos envolvidos da área, que também sinalizaram com suas percepções que a manutenção tem influência no conteúdo da estratégia universitária, não só com seu papel de apoiar as atividades, mas também, de subsidiar as decisões para formar esta referida estratégia.

\section{Limitações da pesquisa}

Dentre os problemas enfrentados na realização da pesquisa está em primeiro lugar à teoria existente acerca da Gestão Estratégica da Manutenção de Equipamentos, principalmente, manutenção voltada para equipamentos científicos de utilização universitária. A quantidade de literaturas existentes que tratam das estratégias voltadas para manutenção de equipamentos, especificamente é pouca, o que não acontece com a literatura que trata das estratégias corporativas e do negócio bem como estratégias de manutenção predial.

Além disso, são escassas as alternativas de literatura que abordem da gestão da manutenção de equipamentos voltadas para objetivos científicos - que é o caso das Universidades - se confrontado com a literatura que trata dos assuntos, da qualidade e da gestão da produção em indústrias, por exemplo.

Devido a esses problemas torna-se uma pesquisa delongada por estar na dependência da agenda das pessoas escolhidas para o preenchimento dos questionários, consequentemente torna-se onerosa tendo em vista o número de visitas e o tempo perdido para tal fim.

Ainda que o estudo de caso tenha sido apropriado para este tipo de pesquisa, por permitir descrever o papel e a relação da manutenção com a gestão estratégica universitária, outro ponto importante é lembrar que a limitação metodológica da pesquisa, está em não poder generalizar para outras instituições a partir deste resultado, devido às particularidades existentes na organização estudada.

\section{Algumas sugestões para estudos futuros:}

1. Sugestões de questões que permitem a continuidade da pesquisa:

- Identificar o papel da manutenção em diferentes universidades;

2. Questões que surgiram durante a pesquisa:

- Qual é o papel da logística dentro dos serviços de manutenção de equipamentos? 
- Existem barreiras que impedem o rápido atendimento aos usuários de centros de manutenção em organizações tais como as universitárias? 


\section{REFERÊNCIAS}

ALMEIDA, C. S.; VIDAL, M. C. R. Gestão da Manutenção Predial: a Tecnologia, a Organização e as Pessoas. Rio de Janeiro: Gestalent, 2001.

ALPERSTEDT, G. D.; MARTIGNAGO, G.; FIATES, G. G. S. O processo de adaptação estratégica em uma instituição de ensino superior sob a ótica da teoria institucional. Revista de Ciências da Administração, Santa Catarina, v. 8, n. 15, p. 114-137, 2006.

ARCURI FILHO, R. Medicina de Sistemas: Uma Abordagem Holística, Estratégica e Institucional para a Gestão da Manutenção. Dissertação (Mestrado em Sistemas de Gestão) - Universidade Federal Fluminense, Niterói, 2005.

ASSOCIAÇÃO BRASILEIRA DE NORMAS TÉCNICAS. NBR 5462: Confiabilidade e Manutenabilidade. Rio de Janeiro, 2004.

BASTOS, S. A. P.; MACEDO-SOARES, T. D. L. A. Impacto estratégico dos fatores macro ambientais no desempenho de concessões de serviços públicos: a CEG e a CEG RIO na ótica relacional. Revista de Administração Pública, v. 41, n. 4, p. 733-767, 2007.

BOTH, B. Relações entre estratégia e estrutura Organizacional: Um estudo de caso na URI. 2000. 137 f. Dissertação (Mestrado em Administração) - Escola de Administração da Universidade Federal do Rio Grande do Sul, Porto Alegre, 2000.

BUENO, J. M.; DOMINGUES, C. R.; CORRÊA, F. D. D. Capacitação e Treinamento dos Profissionais da Manutenção e sua Influência na Qualidade e Produtividade de Pequenas e Médias Empresas Entre o Discurso e a Prática. In: SEMINARIO DE GESTAO DE NEGÓCIOS, 2., 2005, Curitiba. Anais... 2005.

BULGACOV, S. Estudo Comparativo e de caso de organizações de estratégias. Organizações e Sociedade. v. 5, n. 11, p. 53-76, jan/abr/1998.

CAPETTI, E. J. O papel da Gestão da Manutenção no Desenvolvimento da Estratégia da Manufatura. 2005. 168f. Dissertação (Mestrado em Engenharia de Produção)-Universidade Católica do Paraná, Curitiba, 2005. Disponível em: http://www.produtronica.pucpr.br/publico/ppgeps/conteudo/dissertacoes/pdf/EdsonCapetti.pd f >. Acesso em: Abril/ 2009

CAVALCANTE, C. A. V.; ALMEIDA, A. T. . Modelo multicritério de apoio a decisão para o planejamento de manutenção preventiva utilizando PROMETHEE II em situações de incerteza. Pesqui. Oper. [online]. 2005, vol.25, n.2, pp. 279-296. ISSN 0101-7438. doi: 10.1590/S0101-74382005000200007. Acesso em: Julho/2009.

CRHISTOPHER, M. Logística e gerenciamento da cadeia de suprimentos. São Paulo: Pioneira, 1997.

CUNHA, F. L. S. A aplicação da aliança logística: estudo de caso em hospitais da Universidade Federal do Ceará. Revista Cent. Ciência Administrativa, Fortaleza, v. 9, n. 2, p. 132-151, dez. 2003. 
CARSTENS, L. O papel da Gestão da Manutenção na Estratégia de Operações. 2007. 163 p. Dissertação (Mestrado em Engenharia de Produção e Sistemas)-Pontifícia Universidade Católica do Paraná. Curitiba, 2007. Disponível em: http://www.produtronica.pucpr.br/publico/ppgeps/conteudo/dissertacoes/pdf/LucianoCarstens .pdf . Acesso em Junho/ 2009

ESTRADA, Rolando J. S. Os Rumos do Planejamento Estratégico na Universidade Pública - Um estudo de caso na Universidade Federal de Santa Maria. 2000. Tese (Doutorado em Engenharia de Produção) - Universidade Federal de Santa Catarina, Santa Catarina, 2000. $206 \mathrm{p}$.

FARIAS, J. S. ; SENNA, E. B. O. S. . Alinhamento da Gestão de Pessoas à Estratégia Organizacional. In: V Encontro de Estudos sobre Empreendedorismo e Gestão de Pequenas Empresas [EGEPE]- 05 a 07 de março/2008, 2008, SÃO PAULO. Anais CD-ROM com os TRABALHOS NA ÍNTEGRA. São Paulo-SP : T.A.C. Multimídia Ltda, 2008.

FERREIRA, A. B. H. Novo Dicionário da Língua Portuguesa. $2^{\text {a }}$ ed. Rio de Janeiro: a Nova Fronteira, 1986.

BRANCO FILHO, G. Dicionário de termos de Manutenção e Confiabilidade. Rio de Janeiro, Editora Ciência. Moderna Ltda., 2000

GALVANI, L. V. Metodologia para minimizar impacto da indisponibilidade não programada sobre a receita do serviço de transmissão de energia elétrica. $2003.135 \mathrm{f}$. Dissertação (Mestrado em Engenharia Elétrica) - Universidade Federal de Santa Catarina, Curitiba, 2003.

GIL, A. C. Métodos e Técnicas de Pesquisa Social. 5ª ed. São Paulo: Atlas, 1999. 207 p.

KARDEC, A.; NASCIF, N. Manutenção: Função Estratégica. $2^{a}$ ed. Rio de Janeiro: Editora Qualitymark, 2001.368 p.

LIMA, F. A.; CASTILHO, J. C. N. Aspectos da Manutenção dos Equipamentos Científicos da Universidade de Brasília. 2006. 53 f. Trabalho de conclusão de curso (Especialização) - Faculdade de Economia, Administração, Contabilidade e Ciência da Informação e Documentação da Universidade de Brasília, Brasília, 2006.

MACHADO, N. S. O relacionamento entre estrutura, poder e estratégia em organizações universitárias: a criação da Universidade do Oeste de Santa Catarina, 2002. 297f. Tese (Doutorado)- Programa de Pós-Graduação em Engenharia de Produção, UFSC, Florianópolis, 2002 .

MARCELINO, G. F.; VICTOR, H. L. Como planejar e estruturar uma organização a partir da Administração Estratégica. Brasília: Mimeo, 1999.

MELlEIRO, M. M.; TRONCHIN, D. M. R.; CIAMPONE, M. H. T. O planejamento estratégico situacional no ensino do gerenciamento em enfermagem. Acta Paulista de Enfermagem. v. 18, no. 2, p. 165-171, 2005. 
MORAES, P. H. A. Manutenção Produtiva Total: estudo de caso em uma empresa automobilística. 2004. 90 f. Dissertação (Mestrado)- Departamento de Economia, Contabilidade e Administração, Universidade de Taubaté, São Paulo, 2004.

MOTTA, P. R. Gestão Contemporânea: a ciência e a arte de ser dirigente. Rio de Janeiro: Editora Record, 1991.

OTANI, M.; MACHADO, W. V. A proposta de desenvolvimento de gestão da manutenção industrial na busca da excelência ou classe mundial. Revista Gestão Industrial, Ponta Grossa, v. 4, n. 2, p. 1-16, abr./jun., 2008.

PEREIRA FILHO, O. R. Gerenciamento Logístico do Fluxo de Informações e Materiais em Unidade Industrial Aeronáutica. 2002. 110 f. Dissertação (Mestrado) - Departamento de Economia, Contabilidade e Administração, Universidade de Taubaté, São Paulo, 2002.

PERES, C. R. C.; LIMA, G. B. A. Análise do Capital Organizacional da Manutenção sob a perspectiva do aprendizado e crescimento do balanced scorecard. 2008. In: Congresso nacional de Excelência em Gestão, 4, 2008.

PINTO, A. K; XAVIER, J. N. Manutenção: função estratégica. ed. 2, Rio de Janeiro: Qualitymark, 2003.

QUINELLO, R.; NICOLETTI, J. R. Inteligência Competitiva nos Departamentos de Manutenção Industrial no Brasil. Revista de Gestão da Tecnologia e Sistemas de Informação, v. 2, n.1, p. 21-37, 2005.

REBELO, L. M. B.; ALMEIDA, I. G. Planejamento Estratégico: uma ferramenta de Gestão para a Administração do Setor Público Estadual do Amazonas. 2008. In: Congresso nacional de Excelência em Gestão, 4., 2008.

REZENDE, D. A. Metodologia para projeto de planejamento estratégico de informações alinhado ao planejamento estratégico: a experiência do SENAC-PR. Ciência da Informação, v. 32, n. 3, p. 146-155, set./dez. 2003. SANTOS JR., J. N. Planejamento de serviços de ICT. Ciência da Informação, v. 25, n. 1, p. 47-51, jan./abr. 1996.

ROCHA, W. Contribuição ao Estudo de um Modelo Conceitual de Sistema de Informação de Gestão Estratégica. 1999. 158f. Tese (Doutorado)- Faculdade de Economia, Administração e Contabilidade da Universidade de São Paulo, São Paulo.

ROESCH, S. M. A. Projeto de Estágio do Curso de Administração. São Paulo: Atlas S/A, 1996.

RONDON, M. B.; Análise da Gestão Estratégica da Embasa. 2004. 171f. Dissertação (Mestrado) - Fundação Escola de Administração, Universidade Federal da Bahia. Salvador, 2004.

SELLITTO, M. Formulação estratégica da manutenção industrial com base na confiabilidade dos equipamentos. Revista Produção, S. Paulo, v. 15, n. 1, p. 44-59, 2005. 
SILVA, F. B. Conceitos e Diretrizes para a Gestão da Logística no Processo de Produção de Edifícios. 2000. 206 p. Dissertação (Mestrado) - Escola Politécnica da Universidade de São Paulo. São Paulo, 2000.

SILVEIRA, L. A. Relação Universidade-Empresa: Processo de Transferência de Tecnologia nas Empresas Catarinenses. Florianópolis: Imprensa Universitária, 2006.

STEVENSON, W. J. Estatística aplicada à Administração. São Paulo: Harper \& Row, 1981.

TAVARES, L. Administração moderna da manutenção. Rio de Janeiro, Novo Pólo Publicações, 1999.

TEIXEIRA, A. A universidade de ontem e hoje: Anísio Teixeira. Rio de Janeiro: UERJ, 1998., (Coleção Universidade, 3).

TRIGUEIRO. M. G. S. Universidades públicas: desafios e possibilidades no Brasil contemporâneo. Brasília: Editora da Universidade de Brasília, 1999. p. 15-43.

TROES, L. G. Viabilização de Implementação da Gestão da Manutenção em Micro e Pequenas Empresas. 2007. 59f. Trabalho de Conclusão de Curso (Graduação em Engenharia de Produção) - Departamento de Engenharia Mecânica do Centro de Ciências Exatas e Tecnologia, Universidade de Caxias do Sul, Rio Grande do Sul, 2007.

VERGARA, S. C. Projetos e Relatório de Pesquisa em Administração. São Paulo: Atlas, 2000.

VERGER, J. As universidades na Idade Média. São Paulo: Editora das Universidades Estadual Paulista, 1990.

WYREBSKI, J. Manutenção Produtiva Total - Um modelo adaptado. 1997. Dissertação (Mestrado em Engenharia de Produção) - Universidade Federal de Santa Catarina, Florianópolis, 1997. Disponível em: http://www.eps.ufsc.br/disserta98/jerzy/. Acesso em: Abril/ 2009. 


\section{APÊNDICE: Instrumento de Coleta de Dados - Questionário}

Prezado (a) Senhor (a):

Sou aluna do Curso de Especialização em Gestão Universitária do Programa de Pós-Graduação em Administração da FACE/UnB. Atualmente estou em fase final de desenvolvimento da minha Monografia cujo objetivo é averiguar a influência da gestão estratégica da manutenção no contexto da Gestão Estratégica da Universidade de Brasília.

As informações prestadas por V. S. ${ }^{a}$ serão tratadas sigilosamente. Por favor, responda todos os itens do questionário com atenção e precisão.

Para responder, você deverá marcar com um "X" a opção que melhor expressa sua avaliação sobre o objeto em questão.

Atenciosamente,

Danielle Silva Coelho

Por favor, leia atentamente essas afirmativas e avalie o quanto cada uma delas descreve o que você pensa em relação à influência da área de manutenção de equipamentos no contexto da Gestão Estratégica Universitária. Para responder cada questão, utilize a seguinte escala:

\section{DISCORDO TOTALMENTE (1) (2) (3) (4) (5)CONCORDO TOTALMENTE}

Quanto mais próximo do número UM você se posicionar, MENOS você concorda com a afirmativa. Quanto mais próximo do número CINCO você se posicionar, MAIS você concorda com a afirmativa.

\begin{tabular}{|l|l|l|l|l|l|}
\hline & $\mathbf{1}$ & $\mathbf{2}$ & $\mathbf{3}$ & $\mathbf{4}$ & $\mathbf{5}$ \\
\hline $\begin{array}{l}\text { A gestão estratégica da manutenção dos equipamentos cria, dentro das } \\
\text { atividades exercidas pela Universidade, nova oportunidades como a } \\
\text { diminuição de custos }\end{array}$ & & & & \\
\hline $\begin{array}{l}\text { A área de manutenção dos equipamentos contribui com o processo de } \\
\text { formulação estratégica da Universidade como um todo. }\end{array}$ & & & & \\
\hline $\begin{array}{l}\text { A área de manutenção dos equipamentos tem influência nas decisões de } \\
\text { planejamento da estratégia da Universidade. }\end{array}$ & & & & \\
\hline $\begin{array}{l}\text { A qualidade dos serviços entregues aos usuários depende dos equipamentos } \\
\text { e processos controlados pela área de manutenção de equipamentos. }\end{array}$ & & & & & \\
\hline $\begin{array}{l}\text { O desempenho da área de manutenção de equipamentos tem influenciado } \\
\text { direta nos resultados obtidos pela Universidade. }\end{array}$ & & & & & \\
\hline & & & & & \\
\hline
\end{tabular}




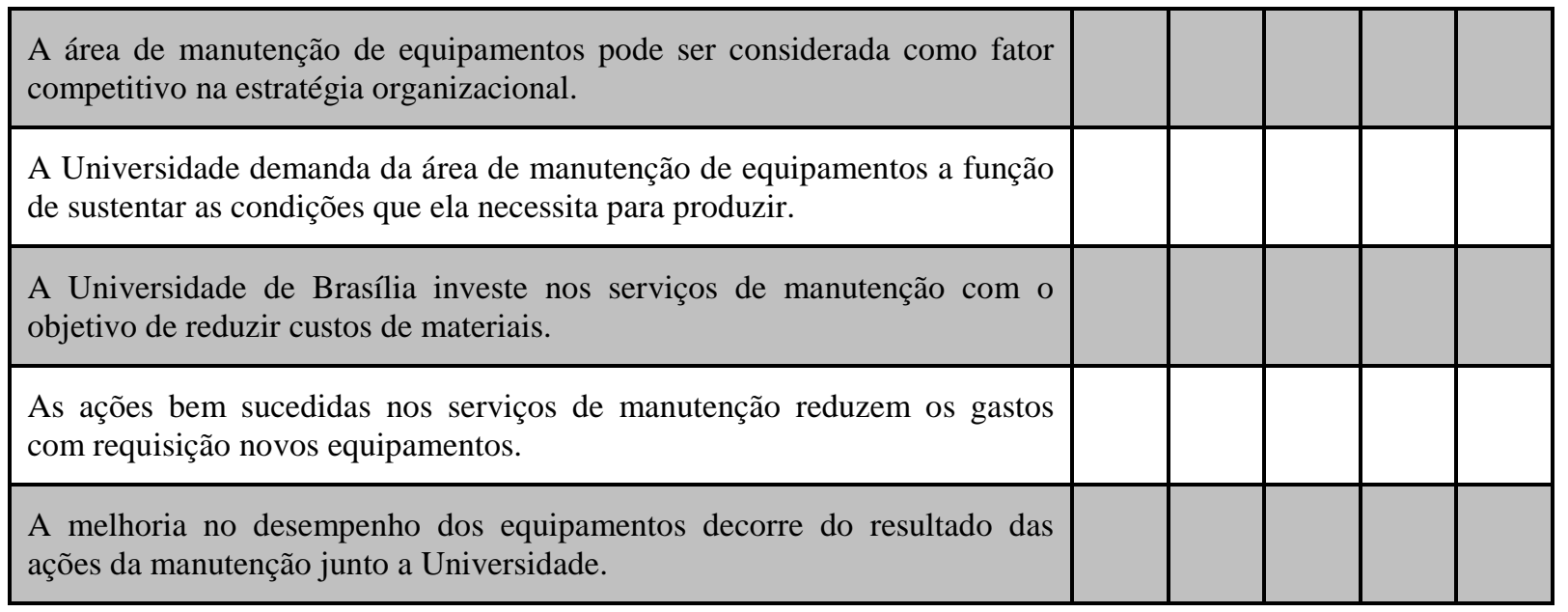

\section{Qual a sua idade?}
a) 18 a 25 anos
b) 26 a 30 anos
c) 31 a 35 anos
d) 36 a 40 anos
e) 41 a 45 anos
f) Acima de 46 anos

\section{Sexo:}

( ) Masculino ( ) Feminino

\section{Qual a sua maior formação?}

a) Ensino Básico ou Fundamental

b) Ensino Médio

c) Técnico

d) Graduado

e) Pós-Graduado

\section{Em que nível funcional você atua?}
a) Auxiliar
b) Assistente
c) Técnico
d) Supervisão

\section{Há quanto tempo atua na área?}
a) 0 a 4 anos
b) 5 a 8 anos
c) 9 a 12 anos
d) 13 a 16 anos
e) 17 a 20 anos
f) Acima de 21 anos

\section{Qual o seu vínculo empregatício?}
a) Funcionário do Quadro Permanente
b) Colaborador Terceirizado
c) Prestador de Serviços
d) Estagiário/ Bolsista 